\title{
Liver precursor cells increase hepatic fibrosis induced by chronic carbon tetrachloride intoxication in rats
}

\author{
Marie-Noële Chobert ${ }^{1,2, *}$, Dominique Couchie ${ }^{2,3, *}$, Agnès Fourcot ${ }^{2}$, Elie-Serge Zafrani ${ }^{1,2,4}$, Yannick Laperche ${ }^{1,2}$, \\ Philippe Mavier ${ }^{2}$ and Arthur Brouillet ${ }^{1,2}$
}

Hepatic fibrosis, the major complication of virtually all types of chronic liver damage, usually begins in portal areas, and its severity has been correlated to liver progenitor cells (LPC) expansion from periportal areas, even if the primary targets of injury are intralobular hepatocytes. The aim of this study was to determine the potential fibrogenic role of LPC, using a new experimental model in which rat liver fibrosis was induced by chronic carbon tetrachloride $\left(\mathrm{CCl}_{4}\right)$ administration for 6 weeks, in combination with chronic acetylaminofluorene treatment (AAF), which promotes activation of LPC compartment. Treatment with $\mathrm{CCl}_{4}$ alone caused a significant increase in serum transaminase activity as well as liver fibrosis initiating around central veins and leading to formation of incomplete centro-central septa with sparse fibrogenic cells expressing $\alpha$-smooth muscle actin ( $\alpha \mathrm{SMA})$. In AAF/CCl 4 -treated animals, the fibrogenic response was profoundly worsened, with formation of multiple porto-central bridging septa leading to cirrhosis, whereas hepatocellular necrosis and inflammation were similar to those observed in $\mathrm{CCl}_{4}$-treated animals. Enhanced fibrosis in $\mathrm{AAF} / \mathrm{CCl}_{4}$ group was accompanied by ductule forming LPC expanding from portal areas, $\alpha$ SMA-positive cells accumulation in the fibrotic areas and increased expression of hepatic collagen type 1, 3 and 4 mRNA. Moreover, CK19-positive LPC expressed the most potent fibrogenic cytokine transforming growth factor- $\beta$ (TGF $\beta$ ) without any expression of $\alpha \mathrm{SMA}$, desmin or fibroblastspecific protein-1, demonstrating that LPC did not undergo an epithelial-mesenchymal transition. In this new experimental model, LPC, by expressing TGF $\beta$, contributed to the accumulation of $\alpha$ SMA-positive myofibroblasts in the ductular reaction leading to enhanced fibrosis but also to disease progression and to a fibrotic pattern similar to that observed in humans.

Laboratory Investigation (2012) 92, 135-150; doi:10.1038/labinvest.2011.143; published online 26 September 2011

KEYWORDS: epithelial-mesenchymal transition; fibrosis; liver progenitor cells; TGF $\beta$

Hepatic fibrosis is the major complication of virtually all types of chronic liver damage (eg. viral, alcoholic liver disease or non-alcoholic fatty liver disease). In humans, fibrosis that ultimately leads to cirrhosis initiates predominantly in the portal areas even though the primary targets of injury are hepatocytes within the lobule. ${ }^{1}$ Impairment of the replicative capacity of most remnant hepatocytes induces an alternate regenerative process from liver progenitor cells (LPC). These cells (also called oval cells in rodent) are located in the most peripheral branches of the biliary tree (canal of Hering). ${ }^{2}$ Once activated, LPC proliferate in the portal region and migrate into the hepatic lobule where they undergo further differentiation into hepatocytes or bile duct cells to repopulate the hepatic parenchyma., ${ }^{3,4}$ This proliferative response characterized by the appearance of bile-duct-like structures in humans is referred to atypical ductular reaction. ${ }^{5}$ LPC have been of increasing interest in latest years since they could have a role not only in regeneration but also in fibrogenesis and carcinogenesis. ${ }^{6}$ In experimental models and various human liver diseases, LPC expand in close proximity to $\alpha$-smooth muscle actin ( $\alpha \mathrm{SMA})$-positive cells deriving from either sinusoidal hepatic stellate cells (HSC) or portal fibroblasts depending upon the location of the injury in the lobule. ${ }^{2,7}$ There are increasing data demonstrating an intimate cross-talk between LPC and $\alpha$ SMA-positive myofibroblasts ${ }^{3,8-11}$ and several studies in rodent models and human diseases have pointed out a strong relationship between severity of fibrosis and intensity of the ductular

\footnotetext{
${ }^{1}$ INSERM, U955, Equipe 17, Institut Mondor de Recherche Biomédicale, Créteil, France; ${ }^{2}$ Université Paris-Est, Créteil, France; ${ }^{3}$ INSERM, U955, Equipe 21 , Créteil, France and ${ }^{4}$ Département de Pathologie, AP-HP, Groupe Hospitalier Henri Mondor, Créteil, France

Correspondence: Dr A Brouillet, PhD, INSERM, U955, Equipe 17, Institut Mondor de Recherche Biomédicale, Créteil F-94010, France.

E-mail: arthur.brouillet@inserm.fr

*These authors contributed equally to this work.

Received 17 March 2011; revised 3 August 2011; accepted 4 August 2011
} 
reaction. ${ }^{12-15}$ Interactions between LPC and sinusoidal HSC or portal fibroblasts are poorly understood but their activation could occur independently, successively or in tandem through similar stimuli. ${ }^{16}$ First, it can be considered that secretion of profibrogenic cytokines and growth factors by LPC could participate to portal fibrosis by inducing HSC or portal fibroblast activation, ${ }^{17,18}$ but this implication of LPC in fibrosis has not been clearly shown in vivo. On the opposite, activation of HSC or portal fibroblasts into myofibroblasts producing extracellular matrix (ECM) and growth factors precedes LPC expansion and differentiation in periportal regions along a porto-venous axis. ${ }^{6,11}$ Recently, it has been shown that inhibition of HSC activation greatly diminished LPC expansion. ${ }^{19}$ Therefore, HSC or portal fibroblast activation seems a prerequisite for LPC expansion, as already demonstrated in other stem cell niches. ${ }^{20}$ Additionally, myofibroblast-LPC cross-talk could indirectly enhance fibrogenesis by recruiting cells of innate immune response, such as leukocytes required for wound healing. ${ }^{21}$ Among the large variety of factors secreted by myofibroblasts, transforming growth factor- $\beta$ (TGF $\beta$ ), the most potent fibrogenic cytokine, is also a well-established mediator of epithelial-mesenchymal transition (EMT), which contributes to fibrosis following injury in several organs including the liver. ${ }^{22-26}$

To investigate the fibrogenic potential of LPC, we established a new model in the rat in which persistent LPC expansion induced by a chronic 2-acetylaminofluorene (AAF) treatment was combined to the well-established model of liver fibrosis using chronic carbon tetrachloride $\left(\mathrm{CCl}_{4}\right)$ injection. ${ }^{1}$ Metabolism of $\mathrm{CCl}_{4}$ into highly reactive $\mathrm{CCl}_{3}$ radicals by cytochrome $\mathrm{P} 450$ is responsible for centrilobular hepatocellular necrosis, which triggers matrix deposition starting around the central veins, with gradual formation of septa bridging neighboring central veins, without any ductular reaction. ${ }^{25}$ In our model, administration of AAF before and during $\mathrm{CCl}_{4}$ treatment blocks the proliferative hepatocyte response caused by $\mathrm{CCl}_{4}$-induced necrosis ${ }^{27}$ and leads to the emergence of an alternate regenerative pathway with expansion of LPC in periportal regions as commonly reported in human fibrosis of various etiologies. ${ }^{12-14,28}$ Using this new model, we investigated the involvement of LPC activation in fibrosis development by comparing the fibrogenic response in rats treated with a combination of $\mathrm{CCl}_{4}$ and $\mathrm{AAF}$ to that obtained in animals treated with either $\mathrm{CCl}_{4}$ or AAF alone. We also investigated whether LPC may directly participate to fibrogenesis and serve as a source of myofibroblasts through EMT as reported for hepatocytes and biliary cells. ${ }^{22-26}$

\section{MATERIALS AND METHODS}

\section{Animals and Experimental Design}

Male Sprague Dawley rats (200g, Janvier Animal Center) received intraperitoneal injection of $\mathrm{CCl}_{4}$ (Sigma-Aldrich) diluted $1 / 1$ in olive oil twice a week in combination with 2 -acetylaminofluorene $(0.02 \%$ AAF in pellet form, Genestyl) treatment $\left(\mathrm{AAF} / \mathrm{CCl}_{4}\right.$ group, $\left.n=27\right)$ for 6 weeks. $\mathrm{AAF}$ was given 5 days before the first $\mathrm{CCl}_{4}$ injection. In a preliminary study, a continuous AAF exposition in association with a commonly used $\mathrm{CCl}_{4}$ dose $(2 \mathrm{ml} / \mathrm{kg}$ of body weight) was not well tolerated leading to a severe weight loss after 4 weeks of treatment and a high rate of animal mortality. For these reasons, we used $2 \mathrm{ml} / \mathrm{kg}$ of body weight for the initial $\mathrm{CCl}_{4}$ injection and half of this dose for subsequent injections (i.e., $1 \mathrm{ml} / \mathrm{kg}$ body weight). From the second week, the AAF treatment was discontinued 3 days a week (replaced by standard chow). Rats were killed 2, 4 or 6 weeks after the first $\mathrm{CCl}_{4}$ injection and $48 \mathrm{~h}$ after the last $\mathrm{CCl}_{4}$ injection and due to significant mortality in this group, 7-9 animals were analyzed per time point. Two other animal groups received either $\mathrm{CCl}_{4}$ only $\left(\mathrm{CCl}_{4}\right.$ group, $\left.n=27\right)$ or AAF only (AAF group, $n=13$ ). An additional group of untreated rats was used as a control and fed a standard rat chow ad libitum (control group, $n=7$ ). The livers were removed from animals under anesthesia and processed as previously described. ${ }^{29}$ Blood samples were collected to measure serum alanine aminotransferase (ALT) activity by using an Advia 1650 automate (Bayer Diasys). Animal manipulations were performed according to the recommendations of the French ethical committee and under the supervision of authorized investigators.

\section{Caspase-3 Activity}

Liver lysates were prepared by homogenization in hypotonic buffer (50 mM HEPES pH 7.5, $100 \mathrm{mM} \mathrm{NaCl}, 1 \%$ NP40, $1 \mathrm{mM}$ EGTA pH 8, $1 \mathrm{mM}$ DTT, protease inhibitor cocktail (Roche)). Homogenates were centrifuged at $10000 \mathrm{~g}$ for $15 \mathrm{~min}$, and extracted proteins $(50 \mu \mathrm{g})$ were tested in duplicate experiments by measuring the proteolytic cleavage of Ac-DEVD-AFC fluorogenic substrate for caspase-3 (Biomol) on microplate reader TriStar LB 941 (Berthold) as previously described. $^{30}$

\section{Histopathological and Immunohistochemical Methods}

Liver injury and fibrosis were assessed on $4 \mu \mathrm{m}$-thick paraffin-embedded liver sections stained with hematoxylin and eosin (H\&E) and picrosirius red, respectively. Immunohistochemistry was carried out on paraffin-embedded or $5 \mu \mathrm{m}$-thick frozen sections, as previously described. ${ }^{29}$ Primary antibodies were mouse monoclonal anti-cytokeratin 19 (CK19) (1:150, Novocastra Laboratories), anti- $\alpha$ SMA (1:1000; Sigma-Aldrich), anti-desmin (1:200; DakoCytomotion), anti-CD68 (1:150; Serotec) and rabbit polyclonal anticollagen 1 (1:200; Serotec) or anti-TGF $\beta$ (1:50; Santa Cruz). Fluorescent labeling of CK19 and CD68 was achieved on $6 \mu \mathrm{m}$ frozen sections using secondary goat anti-mouse IgG Alexa fluor 488 and 555, respectively (1:1000), after incubation with the Image-iT ${ }^{\mathrm{TM}} \mathrm{FX}$ signal enhancer to reduce the background (Invitrogen). Computer-assisted quantitation of the relative surface stained by CD68 on liver section at magnification $\times 100$ was performed with ImageJ $(\mathrm{NIH})$. 
Immunodetection of $\alpha \mathrm{SMA}$ on paraffin-embedded sections used the streptavidin-alkaline phosphatase conjugate (Serotec) and the FastRed substrate systems (Dako). Doublestaining experiments were performed on $6 \mu \mathrm{m}$ frozen sections. Immunofluorescence double staining of collagen 1 and CK19 was revealed with the secondary goat anti-rabbit IgG Alexa fluor 555 and anti-mouse IgG Alexa fluor 488, and double staining of TGF $\beta$ and CK19 with the secondary goat anti-rabbit IgG Alexa fluor 488 and anti-mouse IgG Alexa fluor 555, respectively. When mouse primary antibodies directed against $\alpha \mathrm{SMA}$ or desmin were used, they were incubated alone and detected with goat anti-mouse $\operatorname{IgG}$ Alexa fluor 555. After a 20-min step of permeabilization by $0.2 \%$ triton in PBS, sections were incubated with an antiCK19 antibody directly labeled with mouse IgG Alexa fluor 488 , using Zenon ${ }^{\circledR}$ labeling technology (Invitrogen).

\section{In Situ Hybridization}

Complementary RNA probe specific for $\alpha$-fetoprotein (AFP) and TGF $\beta$ were synthesized using a digoxigenin RNA labeling kit (Roche Diagnostics). The cRNA AFP probes were obtained from a rat cDNA plasmid (gift of Dr JL Danan) digested with XmaI (antisense) or SphI (sense) probe) and transcribed from the SP6 or T7 promoters, respectively. TGF $\beta$ probes were transcribed from a cDNA fragment obtained by RT-PCR from rat liver at day 9 in the AAF/partial hepatectomy model using forward 5'-TACGTCAGACATTCGGG AAGCAGT- $3^{\prime}$ and reverse $5^{\prime}$-TGTACTGTGTGTCCAGGCTC CAAA- $3^{\prime}$ primers which map to positions $553-576$ and $1143-$ 1131 of the rat TGF $\beta$ sequence (GI: 148747597) and subcloned into pCR4-TOPO-plasmid. The cRNA TGF $\beta$ probes were transcribed from T7 and T3 promoters of the plasmid digested with SpeI (antisense) or NotI (sense) and labeling, hybridization and revelation procedures were performed in paraffin sections as previously described. ${ }^{31}$ Detection of AFP or TGF $\beta$ mRNA in consecutive liver sections stained with immunofluorescent anti-CK19 as described above were realized with a standard in situ hybridization protocol on frozen serial sections cut at $5 \mu \mathrm{m}$ thickness (Supplementary Materials).

\section{Quantitative Real-Time PCR}

Total RNA was isolated from frozen hepatic tissue using the RNeasy mini kit (Qiagen). In all, $2 \mu \mathrm{g}$ were reverse transcribed from random hexamers using a first-strand synthesis kit (Fermentas Life Sciences) and specific cDNA amplifications were performed as previously described ${ }^{29}$ using primers listed in Table 1. Relative quantification of gene expression was performed using the $2^{-\Delta \Delta \mathrm{CT}}$ method and ribosomal $18 \mathrm{~S}$ RNA normalization and results were expressed as fold induction over values obtained from control animals.

\section{Liver Collagen Content}

Hydroxyproline assay was performed as previously described, ${ }^{32}$ using small fragments of different lobes that were pooled, lyophilized and hydrolyzed in $6 \mathrm{~N} \mathrm{HCl}$ at $110^{\circ} \mathrm{C}$ overnight. Hepatic hydroxyproline content was spectrophotometrically measured using freshly prepared Ehrlich's reagent and the results were expressed as $\mu \mathrm{g} / \mathrm{mg}$ of tissue (dry weight).

\section{Statistical Analysis}

Liver weight, mRNA and protein analysis (ALT, caspase-3, hydroxyproline) were determined in all animals in duplicate experiments and values are mean \pm s.e.m. of 4-9 separate rats from each group and time point Two-way ANOVA was employed to assess the effect of each treatment over the weeks using Bonferroni post test. The Student's $t$-test was used to compare the differences between the two groups. Statistical analyses were performed with PRISM (GraphPad) and $P$-value of $\leq 0.05$ indicated a significant difference between groups $\left({ }^{\star} P<0.05,{ }^{*} P<0.01\right.$ and $\left.{ }^{* *} P<0.001\right)$.

\section{RESULTS}

\section{Liver Injury}

$\mathrm{CCl}_{4}$ treatment induced hepatocellular necrosis revealed by a gradual increase of serum ALT activity, which reached their maximal values $(238 \pm 33 \mathrm{U} / \mathrm{l})$ at week 6 in group $\mathrm{CCl}_{4}$ (Figure 1a). $\mathrm{CCl}_{4}$ treatment also provoked hepatic apoptosis as revealed by measurement of active caspase- 3 in liver extracts (Figure 1a). No significant differences in necrosis and apoptosis were observed between the $\mathrm{CCl}_{4}$ and $\mathrm{AAF} / \mathrm{CCl}_{4}$ animals by two-way ANOVA, indicating similar liver injury in both groups. Interestingly, AAF-treated animals exhibited low ALT activities but values were significantly higher $(52 \pm 8 \mathrm{U} / \mathrm{l} ; P<0.05)$ than control rats $(37 \pm 5 \mathrm{U} / \mathrm{l})$. In contrast, AAF treatment produced the highest caspase- 3 activity in all liver extracts tested, indicating that chronic AAF exposure alone induced marked hepatic apoptosis associated with a moderate hepatocellular necrosis.

After 6 weeks of treatment, animals from $\mathrm{AAF} / \mathrm{CCl}_{4}$ group had a body weight $(262 \pm 20 \mathrm{~g})$ significantly $(P<0.001)$ lower than in groups $\mathrm{CCl}_{4}$ and $\mathrm{AAF}(370 \pm 28 \mathrm{~g}$ and $367 \pm 16 \mathrm{~g}$, respectively). At the end of the treatment, the ratio of the liver weight to the body weight was increased in both groups of animals treated by $\mathrm{CCl}_{4}$ as compared with untreated rats and induction in the $\mathrm{AAF} / \mathrm{CCl}_{4}$ group was significantly higher than in $\mathrm{CCl}_{4}$ group (Figure $1 \mathrm{~b}$ ).

Livers from group $\mathrm{CCl}_{4}$ exhibited gradual hepatic parenchymal alterations in centrilobular areas with the length of the treatment (Figure 1c), in accordance with increased serum ALT. After 2 weeks of $\mathrm{CCl}_{4}$ treatment, focal necrosis and steatotic hepatocytes were seen around the central veins (data not shown). Two weeks later, livers showed mild-tomoderate steatosis, often associated with inflammatory cell accumulation and bands of damaged tissue connecting central veins of adjacent lobules. After 6 weeks, the hepatic lobular structure was disorganized with moderate hepatocellular steatosis and ballooning in close proximity to inflammatory cells, leading in some cases to complete 
Table 1 Positions on GenBank sequence (GI number) of each rat primer used in quantitative RT-PCR experiments

\begin{tabular}{|c|c|c|c|c|}
\hline Gene & Forward primer $5^{\prime}-3^{\prime}$ & Reverse primer $5^{\prime}-3^{\prime}$ & $\mathrm{Gl}$ & Positions \\
\hline rCCR2 & TCAGGAATCCTCCACACCCTGTIT & TGGAAGGTGGTCAGGAAGAGAACA & 11177913 & $706 ; 845$ \\
\hline rCK19 & GACTTCCTATAGCTATCGCC & TCTGGTACCAGTCGCGAATC & 6429155 & $195 ; 452$ \\
\hline rCOL1 & TAAAGGGTCATCGTGGCTTC & ACCGTTGAGTCCATCTITGC & 109488820 & $3434 ; 3585$ \\
\hline rCOL4 & AGGACAAAAGGGTGATGCTG & CCCTTTGTACCATTGCATCC & 109503586 & $427 ; 591$ \\
\hline rTGF $\beta$ & TGAGTGGCTGTCTITGACG & GGTTCATGTCATGGATGGTG & 148747597 & $724 ; 908$ \\
\hline$r T N F \alpha$ & GACCCTCACACTCAGATCATCTTCT & TGCTACGACGTGGGCTACG & 82524821 & $370 ; 433$ \\
\hline
\end{tabular}

interconnection between central veins and thus dividing the parenchyma into pseudo-lobules centered by a portal tract. In the $\mathrm{AAF} / \mathrm{CCl}_{4}$ group after 2 weeks of treatment, hepatic centrilobular injury was similar to that observed in animals treated with $\mathrm{CCl}_{4}$ alone, except for an expansion of basophilic cells with a high nuclear to cytoplasmic ratio detected in periportal areas (data not shown). After 4 weeks, basophilic cell infiltration extended more deeply into the lobule of $\mathrm{AAF} / \mathrm{CCl}_{4}$-treated rats and formed porto-portal and porto-central bridges. Two weeks later, large areas of basophilic cells delineated multiple nodules in the liver, and hepatic steatosis was localized around these connecting areas. Unexpectedly in the AAF group, we also observed periportal expansion of basophilic cells with small ovoid nuclei, progressively linking adjacent portal areas after 6 weeks of treatment, although there was neither steatosis nor centrilobular necrosis (Figure 1c).

\section{Liver Precursor Cell Expansion}

In groups $\mathrm{AAF}$ and $\mathrm{AAF} / \mathrm{CCl}_{4}$ after 2 weeks of treatment, small basophilic cells arising from portal areas expressed cytokeratin 19 (CK19), a liver precursor cell marker (data not shown). In these two groups, CK19-positive cells increased in number with time and expanded inside the lobule, where they formed duct-like structures (Figure 2a). After 6 weeks in both groups, there was an extensive arborization of CK19positive cells, which extended across the liver lobule, forming bridges between portal tracts. In addition, in group AAF/ $\mathrm{CCl}_{4}$, expansion of CK19-positive cells connected portal and centrilobular areas, dividing the parenchyma into smaller pseudo-lobules. As expected, such an accumulation of CK19positive cells was not detected in $\mathrm{CCl}_{4}$-treated rats, where labeling was restricted to bile duct cells in portal tracts (Figure 2a), as in normal liver (data not shown). These results were confirmed by real-time PCR analysis, which revealed an increase of hepatic CK19 mRNA expression only in $\mathrm{AAF}$ and $\mathrm{AAF} / \mathrm{CCl}_{4}$ groups, peaking at 93-fold over the basal level at weeks 4 and 6 in $\mathrm{AAF} / \mathrm{CCl}_{4}$-treated rats (Figure 2b). No significant difference was observed between the AAF and $\mathrm{AAF} / \mathrm{CCl}_{4}$ groups, suggesting that $\mathrm{CCl}_{4}$ treatment did not contribute to CK19-positive cell expansion induced by AAF. These latter cells organized in ductular structures also expressed AFP mRNA detected by in situ hybridization, confirming their precursor phenotype (Figure 2c). Similar results were obtained on consecutive liver section stained with immunofluorescent antibody against CK19 (red) and in situ hybridization for AFP mRNA (Supplementary Figure S1). In summary, chronic AAF treatment activated the hepatic stem cell compartment leading to LPC proliferation, which was similar in $\mathrm{AAF}$ and $\mathrm{AAF} / \mathrm{CCl}_{4}$ groups. Portocentral connections formed by proliferating LPC and only observed in the $\mathrm{AAF} / \mathrm{CCl}_{4}$ group, seemed to be related to $\mathrm{CCl}_{4}$-induced lesions.

\section{Liver Fibrosis}

As expected, rats treated with chronic $\mathrm{CCl}_{4}$ injection displayed progressive liver fibrosis detected by picrosirius red staining (Figure 3a). At week 2 in group $\mathrm{CCl}_{4}$, fibrosis was first demonstrated around centrilobular venules, with deposition of thin collagen fibers in necrotic and steatotic areas (data not shown). At week 4, we observed gradual formation of fibrous septa interconnecting centrilobular areas, without disorganization of the lobular architecture. After 6 weeks, multiple centro-central fibrotic septa incompletely compassed and divided hepatic lobules. Unexpectedly, in AAFtreated animals after 4 weeks, thin collagen deposition arose from portal tracts and progressed into the lobule in close proximity to the LPC expansion at week 6 (Figure 2a), suggesting that the faint picrosirius red signal might correspond to type 4 collagen accumulation, ${ }^{33}$ a major component of basement membrane associated to LPC activation. ${ }^{2}$ Immunofluorescence detection of collagen 1 revealed an accumulation of this major component of liver fibrosis in group $\mathrm{CCl}_{4}$ (Figure 3b), whereas a faint fluorescent signal was detected in group AAF. In accordance with these observations, real-time PCR analysis (Figure 3c) demonstrated an induction of hepatic mRNA expression of collagen type 1 and 3 in group CCl4 and collagen 4 in group AAF. Thus, the twotimes induction of the hydroxyproline content (Figure $3 \mathrm{~d}$ ) 
a

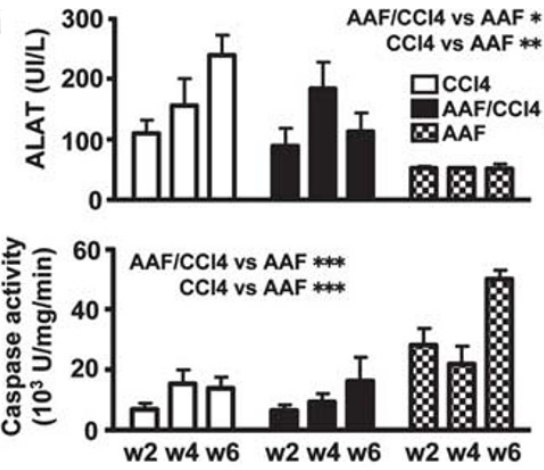

b

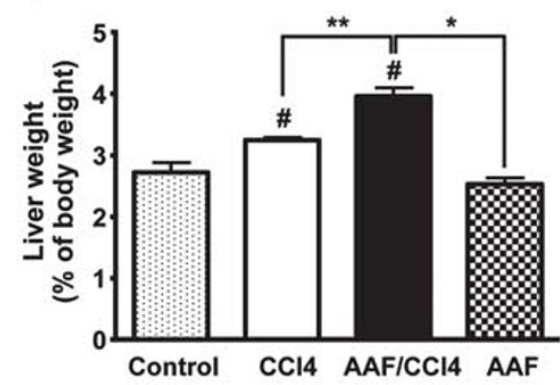

AAF/CCI4

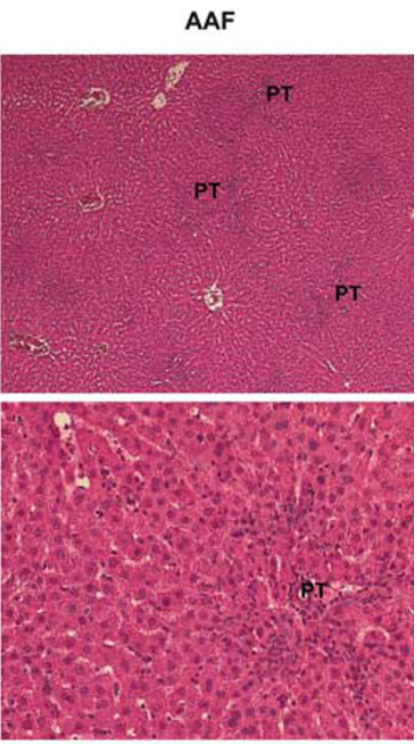

C

$\mathrm{CCl} 4$
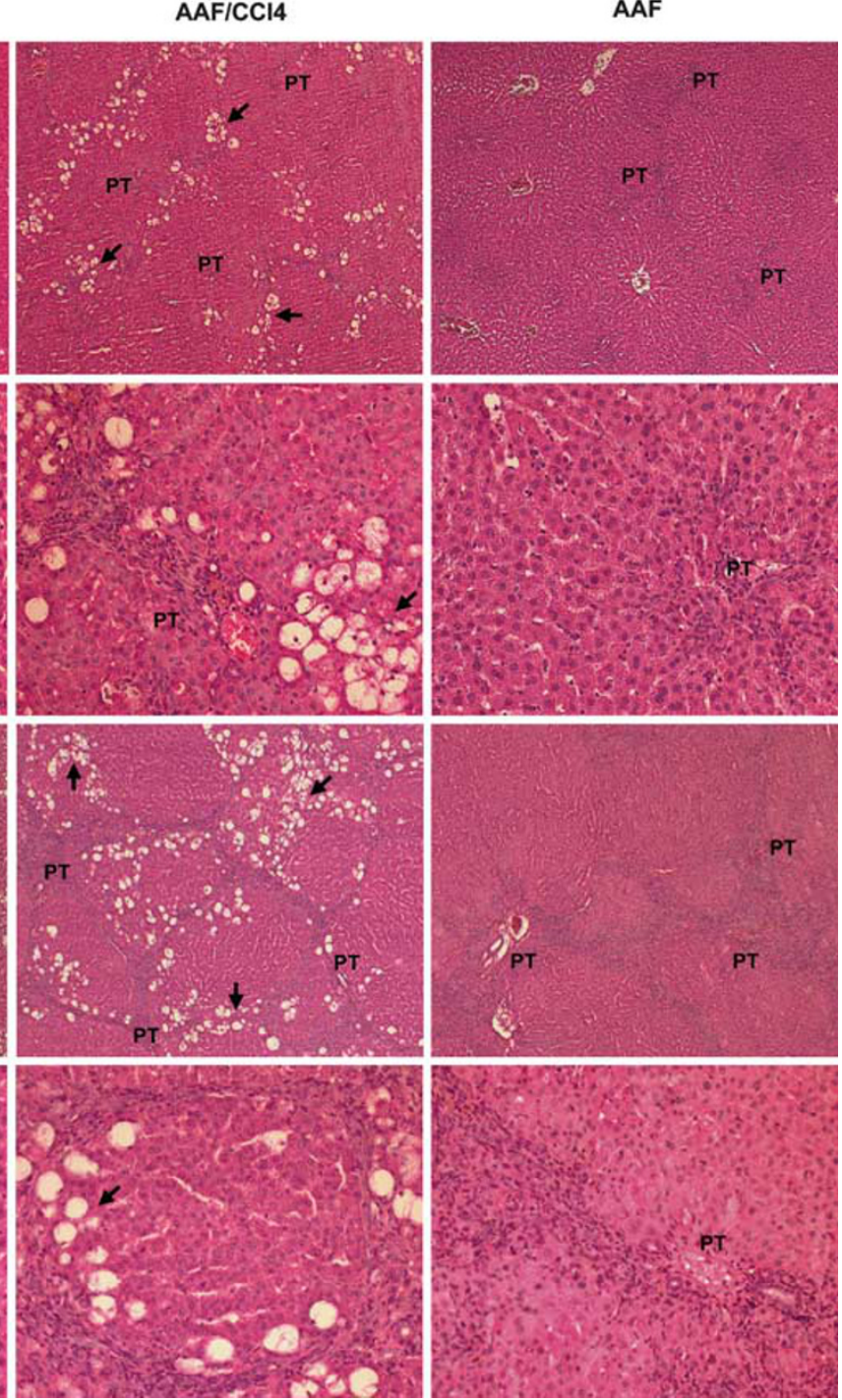

Figure 1 Liver injury and histopathology. (a) Serum ALAT activity was increased to a level that was similar in $\mathrm{CCl}_{4}$ and $\mathrm{AAF} / \mathrm{CCl}_{4}$-treated rats and significantly higher than in AAF-treated rats. Elevation of fluorometric caspase-3 activity was similar in rat liver treated by either $\mathrm{CCl}_{4}$ or $\mathrm{AAF} / \mathrm{CCl}_{4}$ and was significantly higher in AAF-treated animals. (b) The liver weight to body weight ratio was significantly increased in AAF/CCl - treated rats after 6 weeks of treatment as compared with the other groups. ${ }^{\#} P<0.05$ denotes significant difference from control diet and ${ }^{*} P<0.05$ or ${ }^{*} P<0.001$ between $\mathrm{AAF} / \mathrm{CCl} 4$ and $C \mathrm{Cl}_{4}$-treated animals. (c) Representative H\&E staining of liver sections after 4 (W4) and 6 weeks (W6) of treatment (original magnifications $\times 40$ and $\times 400$ as indicated) show steatosis and ballooned hepatocytes (arrows) in $\mathrm{CCl}_{4}$-treated animals $(n=9)$ with formation of centro-central bridges dividing the hepatic parenchyma into lobules centered by portal tracts. In group $\mathrm{AAF} / \mathrm{CCl}_{4}(n=9)$, centrilobular injury was associated with expansion of basophilic cells extending from portal areas and leading to nodules. Proliferation of these cells with small ovoid nuclei in periportal areas was also observed in AAF-treated rats $(n=4)$. PT denotes portal tracts. 
a
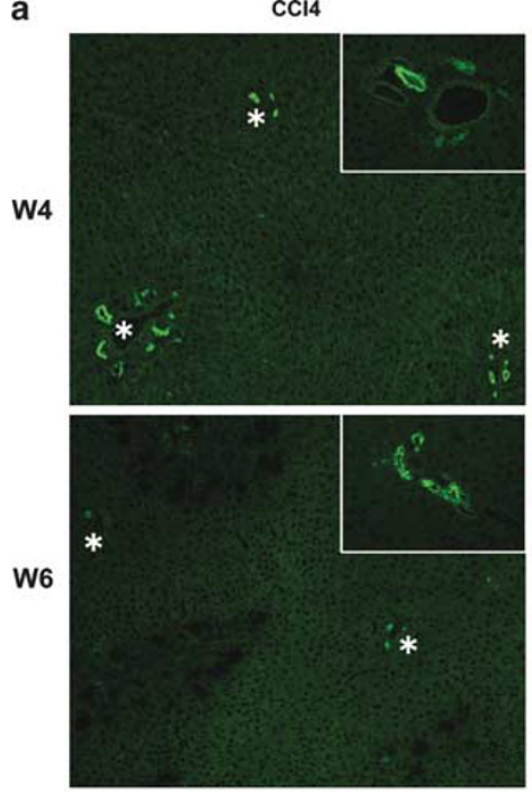

b
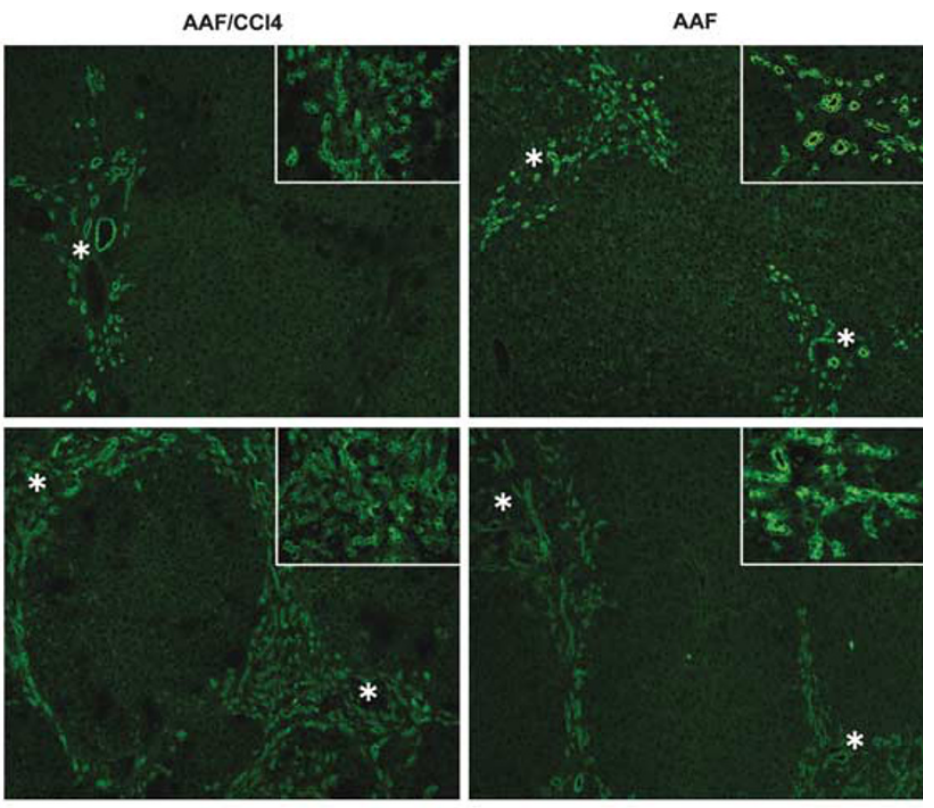

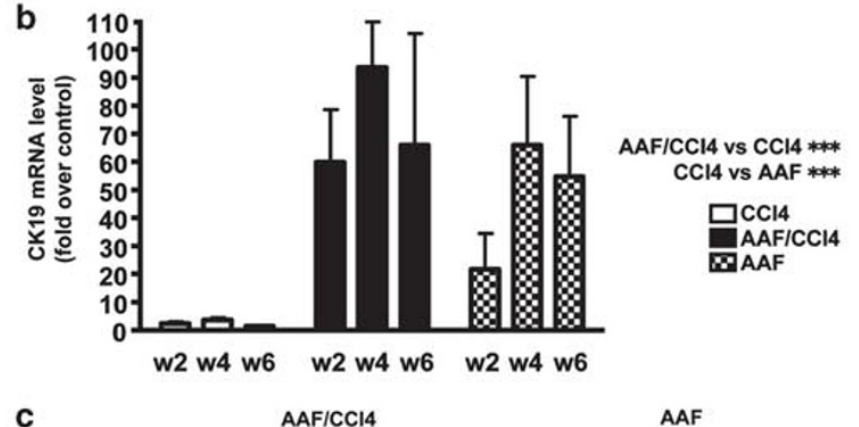

C
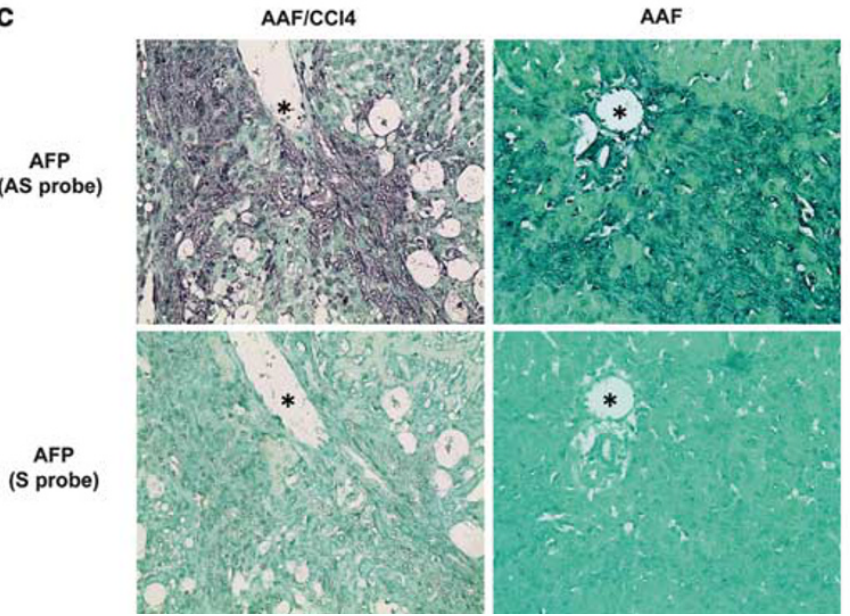

Figure 2 LPC compartment activation. (a) Representative immunofluorescent detection of CK19-positive cells in liver sections revealed an accumulation of LPC in rats treated with AAF $(n=4)$ and AAF/CCl $(n=9)$, arising from portal areas at 4 weeks and expanding inside the lobule after 6 weeks of treatment

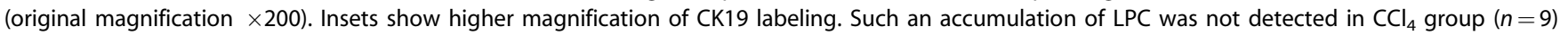
where CK19 labeling was restricted to bile duct cells. (b) Real-time PCR revealed an increase of CK19 mRNA expression only in AAF and AAF/CCl ${ }_{4}$ groups. (c) AFP mRNA detected by in situ hybridization (AFP AS probe) was restricted to cells of the ductular reaction in AAF and AAF/CCl - treated animals. No specific signal was observed using AFP sense probe (original magnification $\times 400$ ). ${ }^{\star}$ denotes portal tract. Images are representative of three independent experiments from three different rat liver sections.

can be accounted by the accumulation of fibrotic collagens in group $\mathrm{CCl}_{4}$ and the extension of basement membrane associated with LPC expansion in group AAF.
In animals treated by a combination of $\mathrm{AAF}$ and $\mathrm{CCl}_{4}$, disease progression and the fibrotic pattern corresponded to the responses above described in both $\mathrm{CCl}_{4}$ and AAF groups 
a

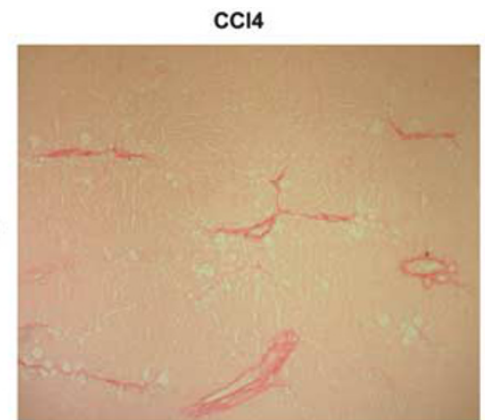

W4

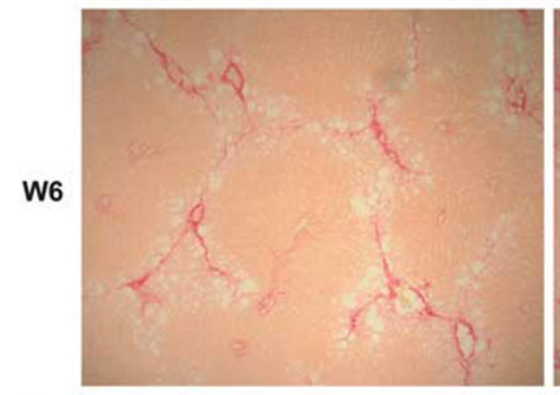

b
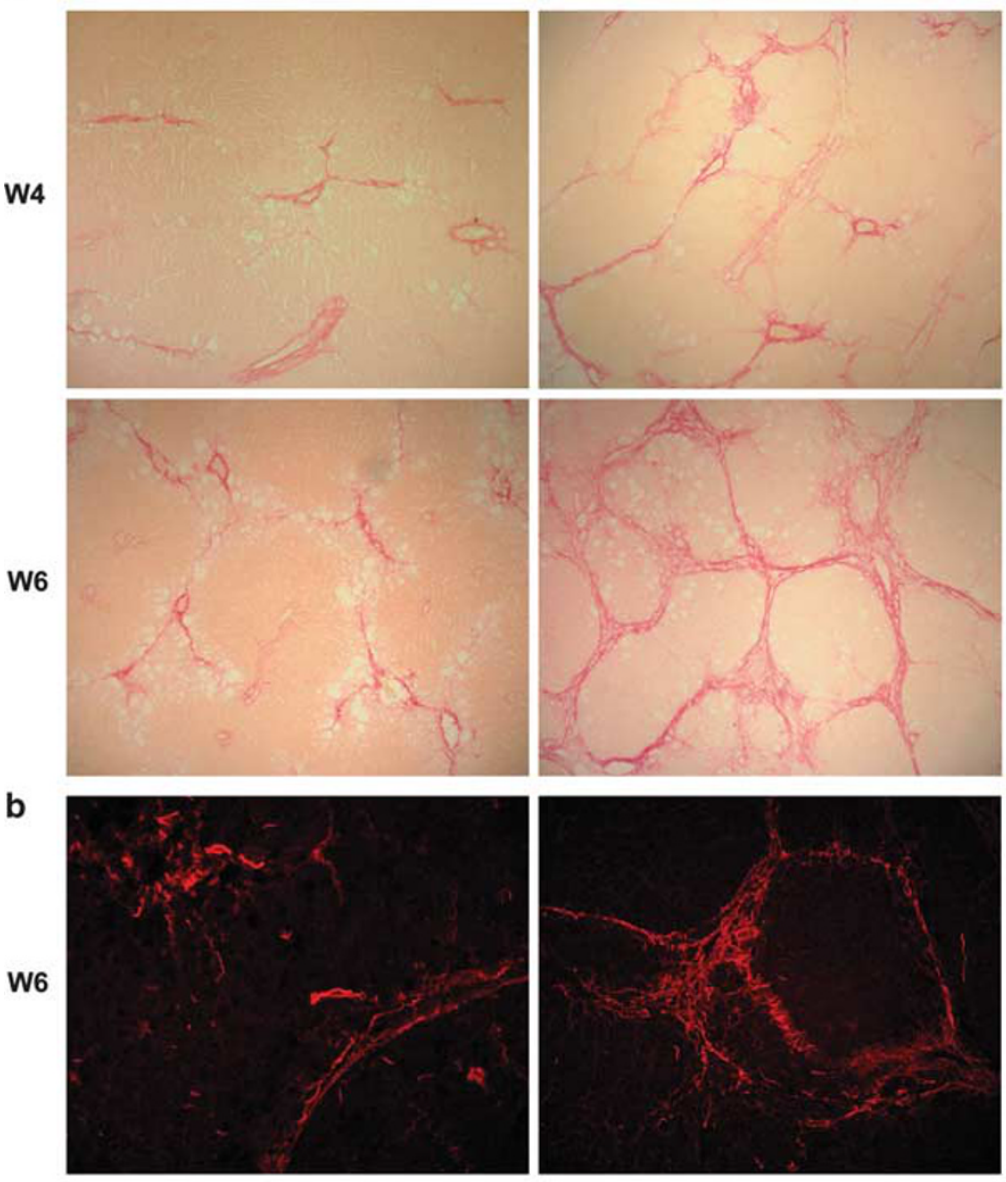

AAFICCl4

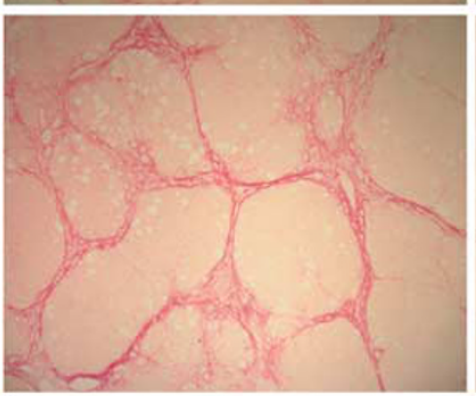

c
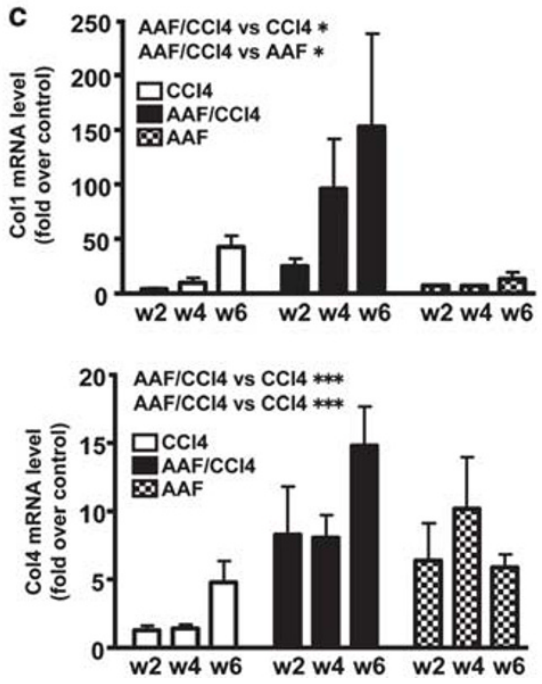
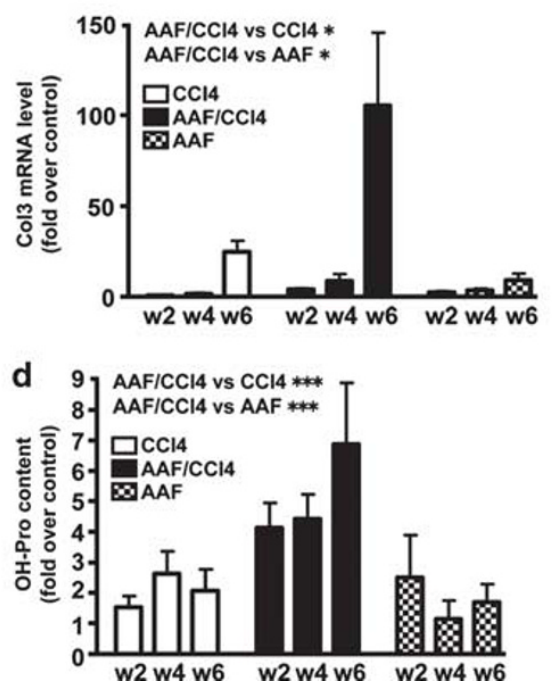

Figure 3 Liver fibrosis. (a) Picrosirius red staining revealed progressive liver fibrosis induced by $\mathrm{CCl}_{4}$ at week 4 , with formation of centro-central fibrous septa at week 6 . In $\mathrm{AAF} / \mathrm{CCl}_{4}$-treated rats, marked fibrosis with porto-central bridging was observed at week 4, leading to cirrhosis at week 6 . In portal areas of animals from AAF group, a faint picrosirius red staining was observed around LPC expansion. Original magnification $\times 100$. Images are representative of 4 (AAF) to $9\left(\mathrm{CCl}_{4}\right.$ or $\left.\mathrm{AAF} / \mathrm{CCl}_{4}\right)$ liver sections. (b) After 6 weeks, immunofluorescent collagen 1 detection revealed strong matrix deposition in perinodular areas from cirrhotic rats liver treated by $\mathrm{AAF} / \mathrm{CCl}_{4}$. A lower collagen accumulation was detected in fibrous septa after $\mathrm{CCl}_{4}$ administration, and a weak labeling was observed in the AAF-induced ductular reaction. Representative fluorescence photomicrographs of two experiments on liver sections from three rats in each group at magnification $\times 200$. (c) Quantitative RT-PCR analysis showed a gradual induction of interstitial collagen type 1 and 3 mRNA enhanced in $\mathrm{AAF} / \mathrm{CCl}_{4}$-treated rats as compared with $\mathrm{CCl}_{4}$ treatment alone. Induction of collagen $4 \mathrm{mRNA}$ was shown only in AAF and AAF/CCl $\mathrm{groups}$

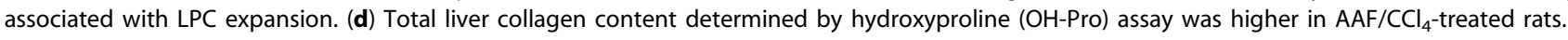


(Figure 3a). After 4 weeks, picrosirius red staining revealed thin fibrous septa from the portal tracts interconnected with larger fibrous scars from central veins, leading to portoportal and porto-central fibrosis. After 6 weeks, fibrosis was more extensive, delineating multiple micronodules and forming complete cirrhosis in all rats from the $\mathrm{AAF} / \mathrm{CCl}_{4}$ group. PCR analysis (Figure 3c) showed significantly increased hepatic mRNA expression of collagen type 1 and 3 , by comparison with that was noted in animals treated only by $\mathrm{CCl}_{4}$ (ANOVA $P<0.05$ ). There was also an induction of hepatic collagen type 4 , similar to that observed in group AAF. An increase of the hydroxyproline content in $\mathrm{AAF} / \mathrm{CCl}_{4}$ group (Figure 3d) up to sevenfold over basal level at week 6, and significantly higher than in $\mathrm{CCl}_{4}$ and $\mathrm{AAF}$ groups (ANOVA $P<0.001$ ), was in accordance with increased fibrosis demonstrated by picrosirius red staining (Figure 3a). Thus, in group $\mathrm{AAF} / \mathrm{CCl}_{4}$, active deposition of basement membrane components during LPC expansion also takes a part in the fibrogenic process, indicating that AAF, while stimulating an expansion of LPC, exacerbates $\mathrm{CCl}_{4}$-induced liver fibrosis.

\section{Liver Inflammation}

$\mathrm{CCl}_{4}$ administration induces an inflammatory response, and macrophages have a critical role in myofibroblastic transformation of HSC and hepatic fibrogenesis. ${ }^{1}$ The amount of liver macrophages, including Kupffer cells and recruited monocytes, was assessed by detection of the pan-macrophage CD68 antigen (Figure 4a). Normal liver displayed a homogenous lobular distribution of CD68-positive cells in accordance with Kupffer cell localization within sinusoids, and CD68 staining covered $2.1 \pm 0.5 \%$ of the liver section as estimated by computer-assisted spot detection method (data not shown). In group $\mathrm{CCl}_{4}$ after 4 weeks, small foci of CD68positive cells accumulated in centro-central septa (Figure 4a), and increased in number with the duration of $\mathrm{CCl}_{4}$ treatment, covering up to $6.3 \%$ of the liver section at week 6 (Figure $4 \mathrm{~b}$ ). In animals treated with AAF alone, the increase in CD68-labeled cells did not significantly differ from that noticed in group $\mathrm{CCl}_{4}$ (Figure $4 \mathrm{~b}$ ), but most positive cells were regularly distributed all over liver lobules (Figure 4a), as noted for CD68-stained Kupffer cells in normal liver. In group $\mathrm{AAF} / \mathrm{CCl}_{4}$, a majority of CD68-positive cells accumulated in the bridging septa above described (Figure 2a). Although extensive fibrosis was observed in $\mathrm{AAF} / \mathrm{CCl}_{4}$ group, the area of the CD68-stained liver tissue was not significantly different from that measured in the group $\mathrm{CCl}_{4}$ (Figure $4 \mathrm{~b}$ ).

During liver injury, activated macrophages secrete numerous cytokines, including tumor necrosis factor- $\alpha$ (TNF $\alpha$ ), which are mitogenic for hepatocytes ${ }^{34}$ as well as for LPC. ${ }^{35,36}$ In $\mathrm{CCl}_{4}$-treated rats, real-time PCR revealed a gradual but limited (less than 4 -fold) induction of TNF $\alpha$ mRNA (Figure 4c) to a level that was not statistically different in $\mathrm{AAF}$ and $\mathrm{AAF} / \mathrm{CCl}_{4}$ groups. Even more, chemokine $\mathrm{C}-\mathrm{C}$ motif receptor 2 (CCR2) mRNA, which is expressed only in recruited monocytes and some $\mathrm{T}$ lymphocytes, ${ }^{37}$ was not different in the three groups (Figure $4 \mathrm{~d}$ ). The low and similar grade of inflammation in the three groups contrasts with the strong difference in fibrosis extension, suggesting that, in our experimental conditions, inflammation had not a major role in the fibrogenic process.

\section{Fibrogenic Liver Cells}

In chronic liver diseases, portal fibroblasts and activated HSC exhibit phenotypic features of myofibroblasts, namely expression of $\alpha$ SMA and ECM proteins. ${ }^{1}$ After 2 and 4 weeks of $\mathrm{CCl}_{4}$ treatment, immunohistochemical staining of $\alpha \mathrm{SMA}$ revealed only a vascular labeling in group $\mathrm{CCl}_{4}$ (Figure 5a), also detected in control livers (data not shown). At week 6, aSMA-positive cells were observed in active fibrotic areas of only three treated animals out of six analyzed (Figure $5 \mathrm{a}$ ). In contrast, in the $\mathrm{AAF} / \mathrm{CCl}_{4}$-treated animals, numerous $\alpha \mathrm{SMA}$ positive cells were seen around portal areas as early as 2 weeks after starting the treatment (Figure $5 \mathrm{a}$ and $\mathrm{b}$ ). The $\alpha \mathrm{SMA}$ labeling was also observed in fibrous septa around centrilobular areas at week 4 and in perinodular fibrosis from cirrhotic rats at week 6 (Figure $5 \mathrm{a}$ and $\mathrm{b}$ ). In the AAF group, whatever the time of treatment, $\alpha$ SMA staining was restricted to vessels as in normal liver and did not reveal any activated HSC in the areas of ductular reaction (Figure 5a). Immunofluorescence detection of $\alpha \mathrm{SMA}$ in frozen liver sections, which provides a higher sensitivity as compared with immunodetection on paraffin sections, confirmed the lack of $\alpha$ SMA-positive cells in the ductular reaction from group AAF and the presence of few activated HSC in fibrous septa in liver from group $\mathrm{CCl}_{4}$ after 6 weeks of treatment (Figure 6a). Immunofluorescence detection of desmin, a hallmark of quiescent and activated HSC, showed an accumulation of positive cells in group AAF, closely associated to LPC expansion extending from periportal areas (Figure 6a). In group $\mathrm{CCl}_{4}$, desmin staining was detected in centrilobularinjured areas and in centro-central fibrous septa. Thus, under our experimental setting $\left(1 \mathrm{ml} / \mathrm{kg}\right.$ of $\left.\mathrm{CCl}_{4}\right)$, the paucity of $\alpha$ SMA staining reflected minor myofibroblastic activation in agreement with moderate fibrosis. In summary, HSC transactivation was clearly shown only in liver from $\mathrm{AAF} / \mathrm{CCl}_{4}{ }^{-}$ treated animals, first in close proximity of LPC arising from portal areas, and then in bridging fibrosis, demonstrating that combination of $\mathrm{CCl}_{4}$ and AAF was necessary to obtain $\alpha$ SMA-positive myofibroblasts, which could account for the high degree of fibrosis in this group.

TGF $\beta$ is the major fibrogenic cytokine mainly produced by $\alpha$ SMA-positive myofibroblasts, ${ }^{1,8}$ and its expression coincides with LPC expansion during liver regeneration after AAF/ partial hepatectomy in rats. ${ }^{17}$ Real-time PCR analysis demonstrated that hepatic mRNA expression of this profibrogenic factor was significantly higher in $\mathrm{AAF} / \mathrm{CCl}_{4}$ group $(P<0.05)$ than in the group that received $\mathrm{CCl}_{4}$ alone (Figure 6b), in accordance with fibrosis extension. Unexpectedly, TGF $\beta$ mRNA induction was higher in AAF 
a
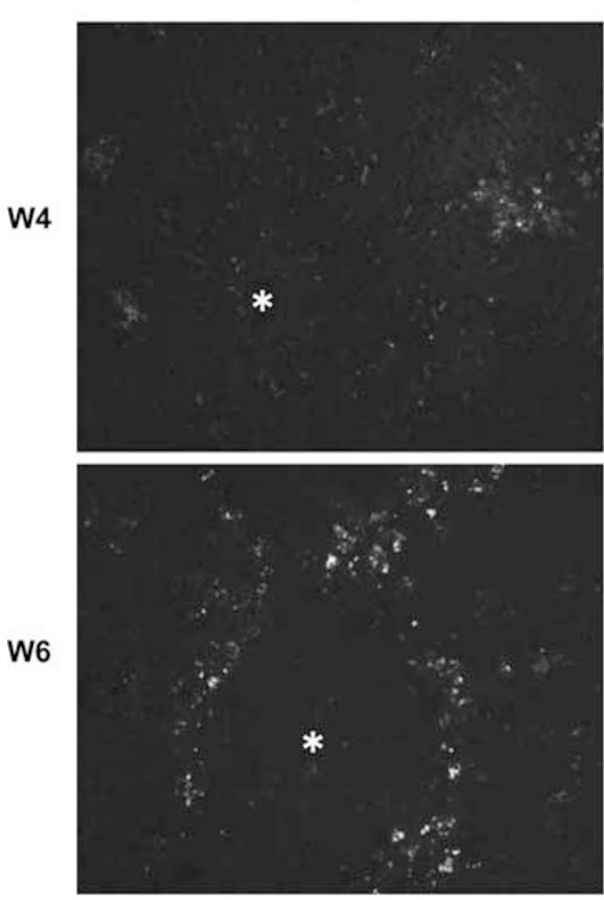

b
$\mathrm{AAF} / \mathrm{CCl} 4$
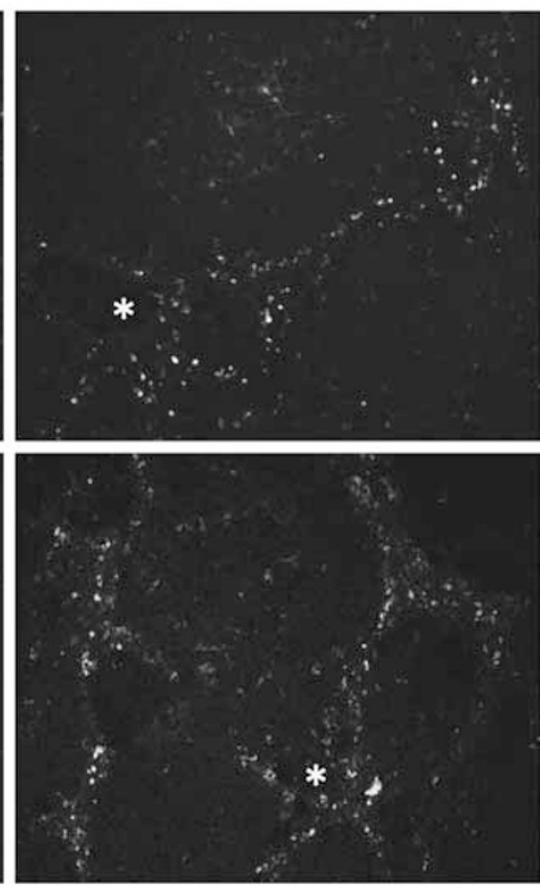

AAF
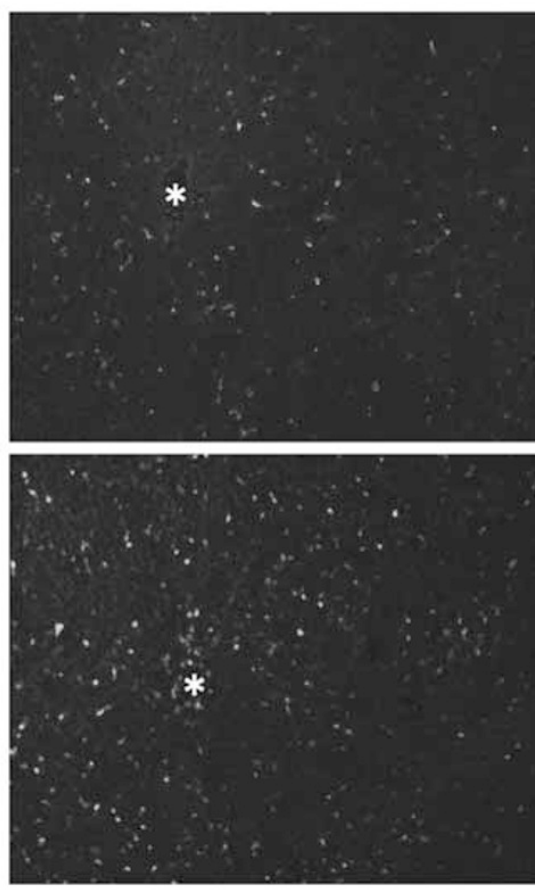

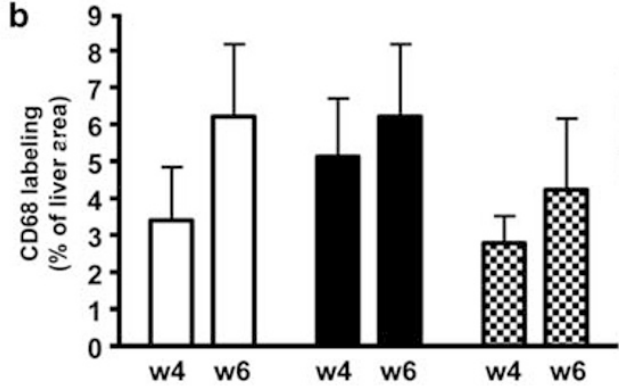

AAF/CCI4 vs AAF *

\section{$\square \mathrm{CCl} 4$}

AAF/CCl4

WAAF
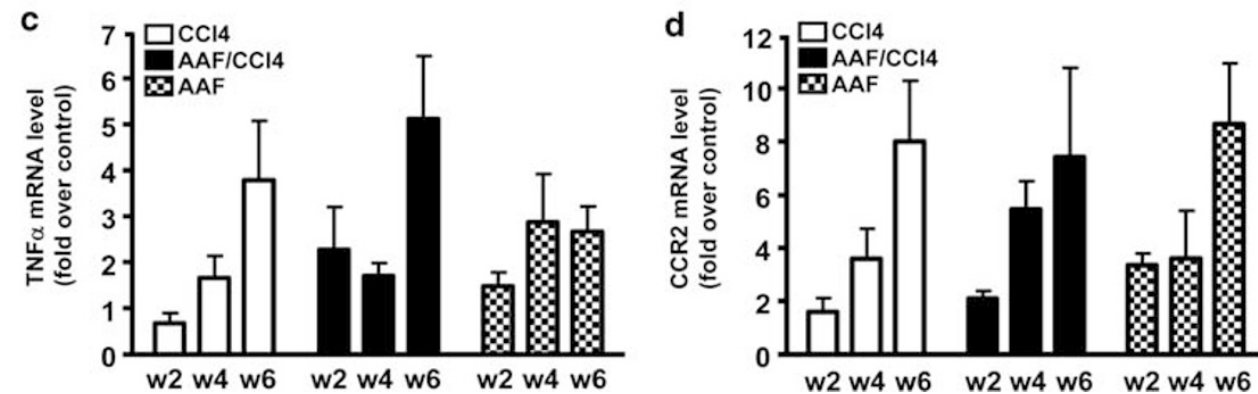

Figure 4 Macrophage recruitment and inflammation. (a) CD68 immunofluorescent detection (original magnification $\times 200)$ revealed positive cells all over liver parenchyma in AAF group, in fibrous septa after $\mathrm{CCl}_{4}$ treatment and in the cirrhotic liver of AAF/CCl 4 -treated animals. Images are representative of 4 (AAF) to $6\left(\mathrm{CCl}_{4}\right.$ or $\left.\mathrm{AAF} / \mathrm{CCl}_{4}\right)$ liver sections. ${ }^{*}$ denotes portal tracts. (b) Quantification of $\mathrm{CD} 68$-positive cells in liver from animals did not reveal a significant difference in the number of hepatic macrophages in $\mathrm{CCl}_{4}$ and $\mathrm{AAF} / \mathrm{CCl}_{4}$ groups after 4 or 6 weeks of treatment. Data are mean values \pm s.e.m. of separate analysis on two fields for each liver section from 4 (AAF) to $6\left(\mathrm{CCl}_{4}\right.$ or $\left.\mathrm{AAF} / \mathrm{CCl}_{4}\right)$ separate rats. Quantitative RT-PCR did not demonstrate quantitative differences in (c) TNF $\alpha$ or (d) CCR2 mRNA expression, revealing that inflammatory response was similar in the three groups.

than in $\mathrm{CCl}_{4}$ group $(P<0.001)$, notably after 2 and 4 weeks of treatment corresponding to the early stages of LPC activation. An increased TGF $\beta$ expression in both groups treated with AAF suggests that LPC are themselves a source of TGF $\beta$, a result that has already been reported. ${ }^{4,38}$ In situ hybridiza- tion studies were performed to identify more precisely the TGF $\beta$-producing cells (Figure $6 \mathrm{c}$ ). In rats treated with AAF alone for 6 weeks, numerous positive cells for TGF $\beta$ mRNA expression were arranged as duct-like structures that deeply invaded the liver from portal areas. In this group without 
a

W2

W4
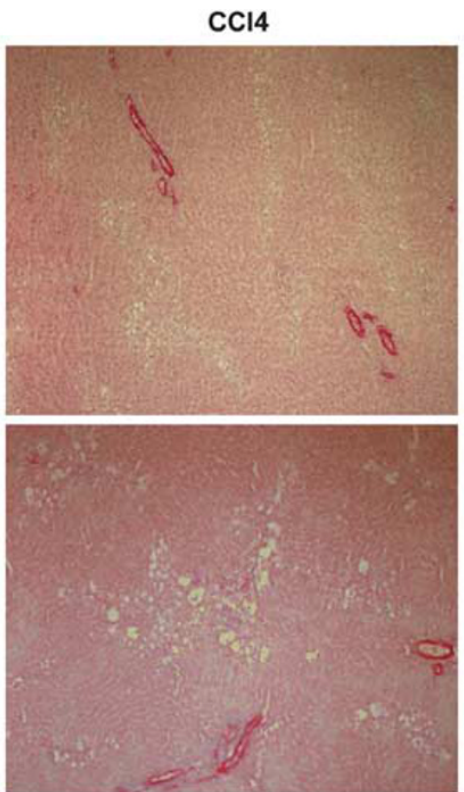

W6

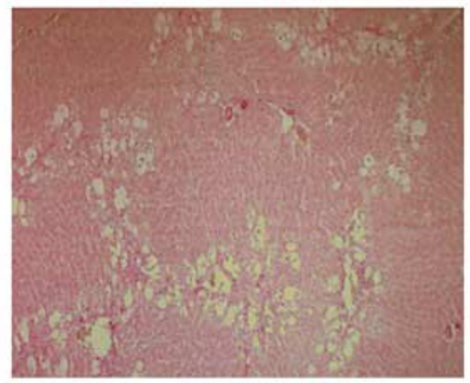

b
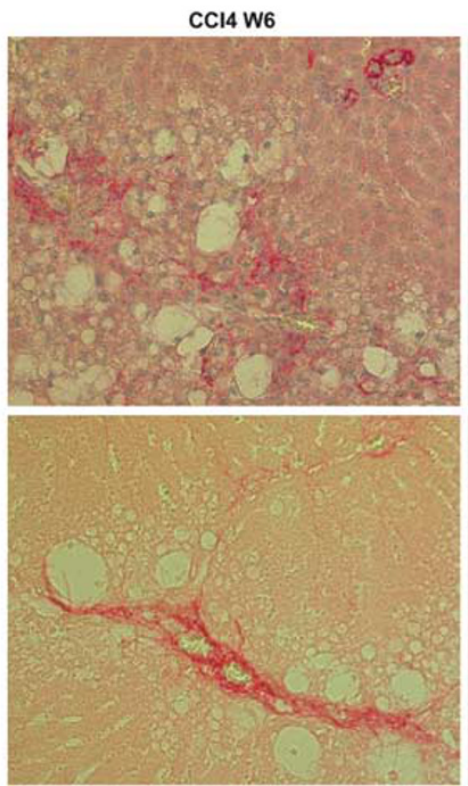

$\mathrm{AAF} / \mathrm{CCl} 4$
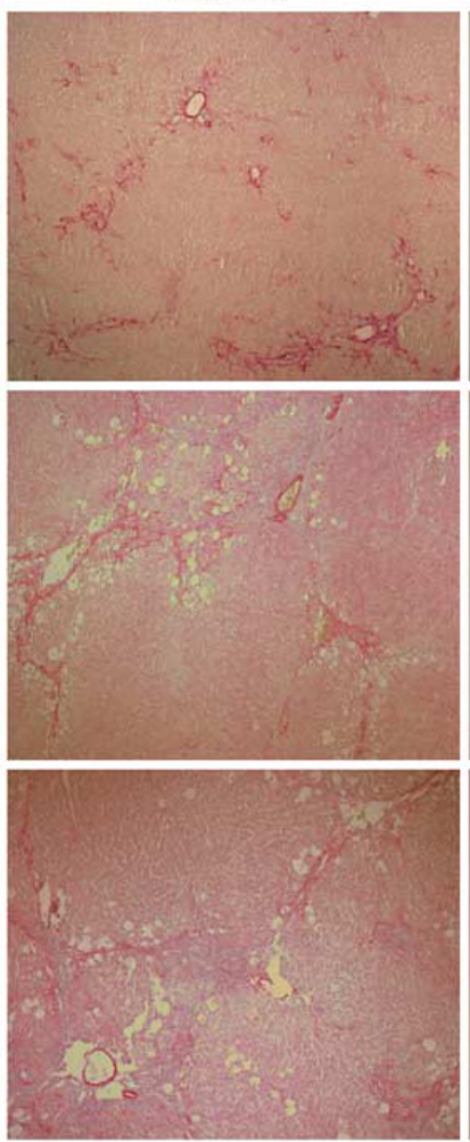

AAF/CCl4 W2
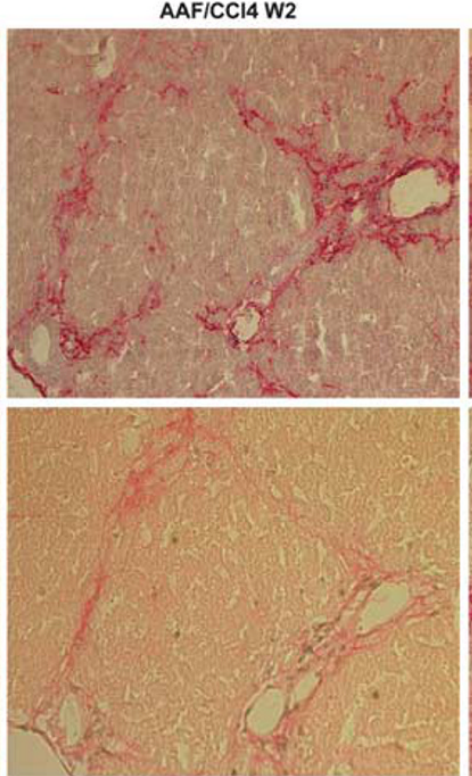

AAF
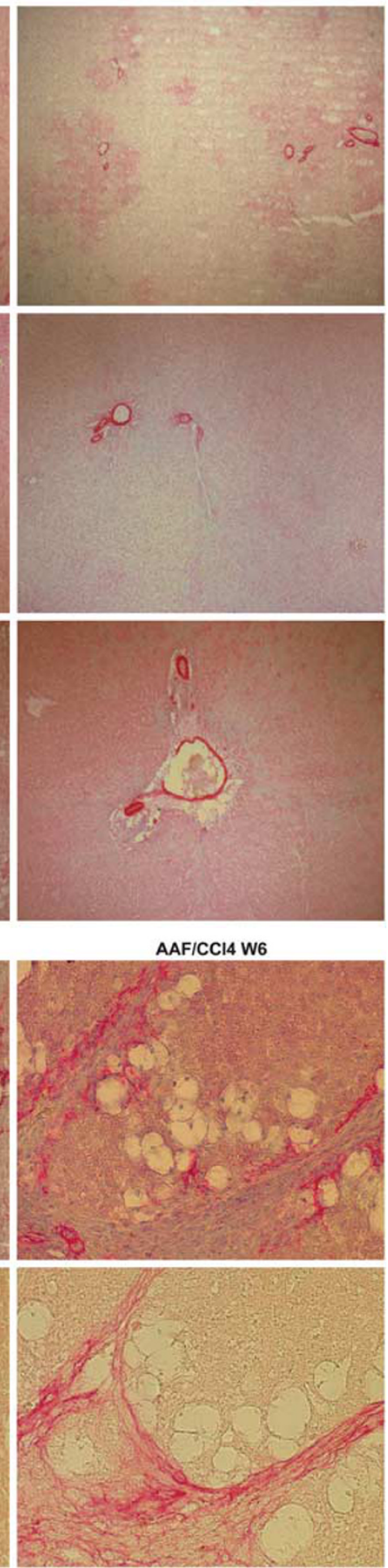

Figure $5 \mathrm{HSC}$ or portal fibroblast activation. (a) Immunohistochemical detection of $\alpha$ SMA-positive cells revealed few activated HSC delineating portal vessels after 6 weeks of $\mathrm{CCl}_{4}$ administration alone. In contrast, numerous positive cells were detected in AAF/CCl 4 -treated rats around portal areas at week 2 , in fibrous septa at week 4 and in perinodular areas at week 6 . No $\alpha$ SMA-positive cell was observed in the ductular reaction in AAF group. Images are representative of 4 (AAF) to $9\left(\mathrm{CCl}_{4}\right.$ or $\left.\mathrm{AAF} / \mathrm{CCl}_{4}\right)$ liver sections at original magnification $\times 100$. (b) After 6 weeks of $\mathrm{CCl}_{4}$ treatment, higher magnification $(\times 400)$ clearly showed $\alpha$ SMA-positive cells in centro-central fibrous septa containing marked collagen deposition revealed by picrosirius red staining. By contrast, in $\mathrm{AAF} / \mathrm{CCl}_{4}$-treated rats, activation of $\mathrm{HSC}$ or portal fibroblasts was early detected at week 2, around the LPC arising in periportal areas faintly stained by picrosirius red. At week 6, $\alpha$ SMA labeling was noted in bridging fibrous septa with large amount of collagen deposition. 
a

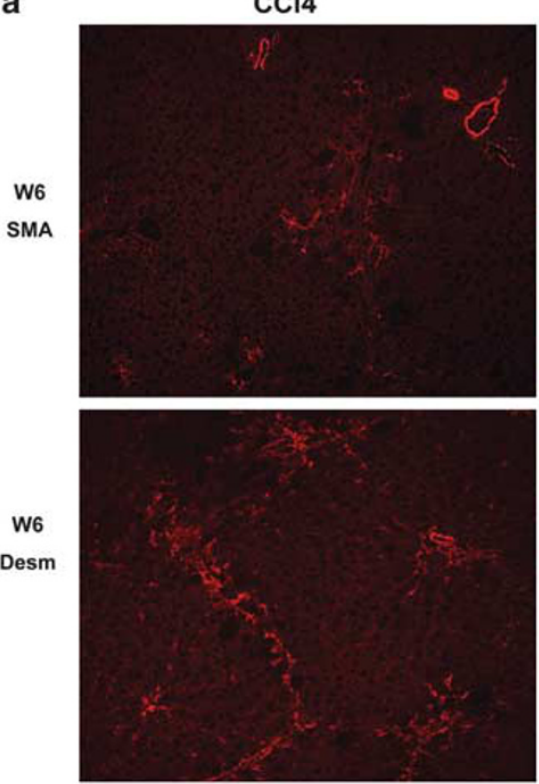

b

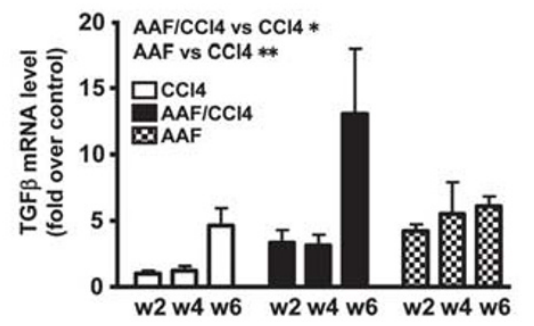

$\mathrm{AAF} / \mathrm{CCl} 4$
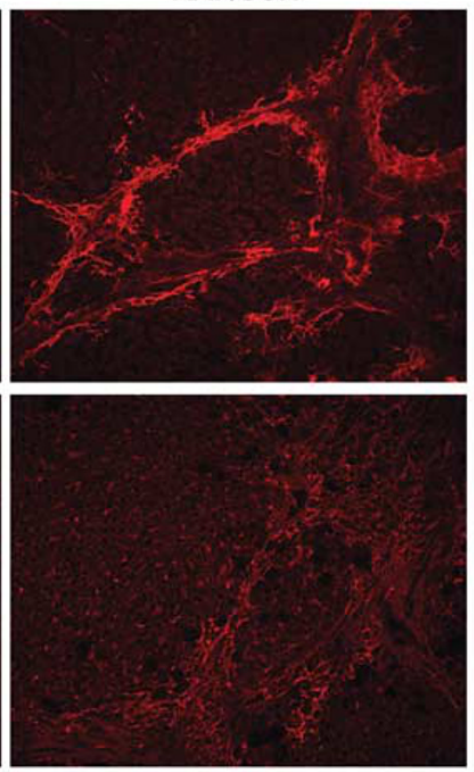

AAF
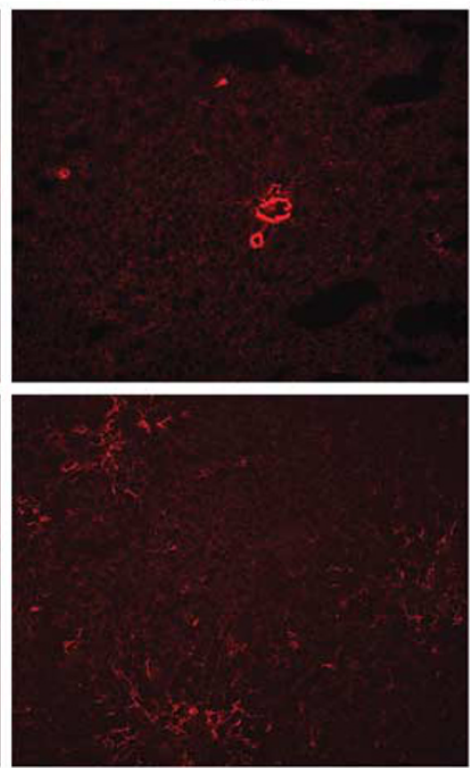

C

AAF/CCI4

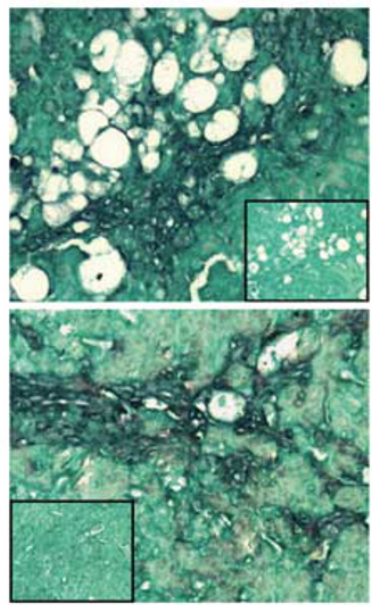

d

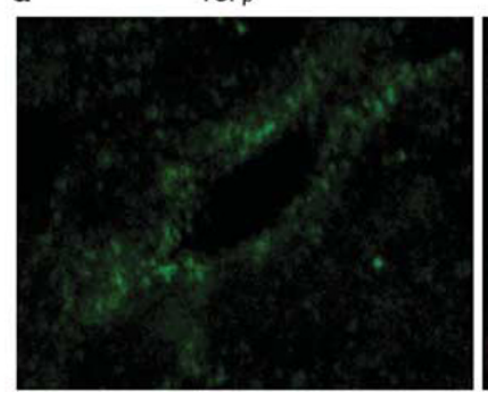

CK19

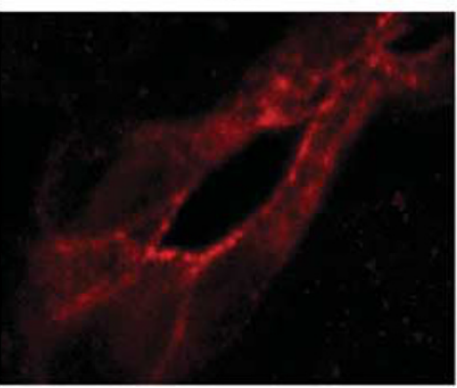

Merge

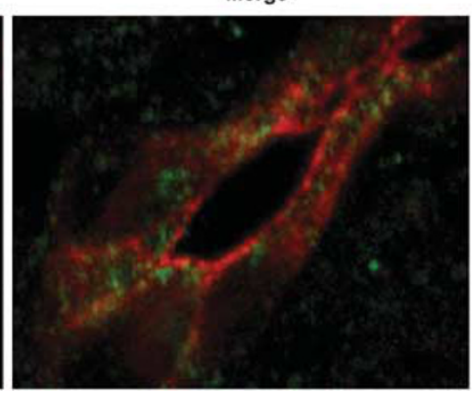

Figure 6 Detection of fibrogenic liver cells. (a) Immunofluorescent detection of $\alpha$ SMA and desmin after 6 weeks of treatment confirms activation of HSC into $\alpha \mathrm{SMA}$-expressing myofibroblasts in cirrhotic liver of $\mathrm{AAF} / \mathrm{CCl}_{4}$-treated rats. Very few $\alpha \mathrm{SMA}$-positive $\mathrm{HSC}$ were noted in fibrous septa after $\mathrm{CCl}_{4}$ administration alone. Lack of activated HSC was observed around the portal areas in the AAF-induced ductular reaction. Representative fluorescence photomicrographs of two experiments on liver sections from two rats in each group at original magnification $\times 200$. (b) Quantitative RT-PCR analysis revealed an enhanced induction of TGF $\beta$ mRNA expression in AAF and AAF/CCl -treated animals and (c) TGF $\beta$ mRNA detection by in situ hybridization showed a strong positive signal in LPC in duct-like structures (inset contains sense probe labeling) in both groups (original magnification $\times 400$ ).

(d) Double-immunofluorescent detection of TGF $\beta$ (green) and CK19 (red) proteins in liver sections from AAF/CCl ${ }_{4}$-treated rats, revealed TGF $\beta$-expressing LPC in merged imaged by confocal analysis. Images are representative of two independent experiments from three different rats in each group. 
$\alpha$ SMA-positive myofibroblasts (Figure 6a), TGF $\beta$ expression was noted in cells previously identified as LPC by CK19 staining (Figure 2a) and AFP expression (Figure 2c). In cirrhotic liver of $\mathrm{AAF} / \mathrm{CCl}_{4}$-treated animals, TGF $\beta$ mRNA expression was detected in perinodular septa, within cells of the ductular reaction (Figure 6c); however, it cannot be excluded that part of the signal could also be attributed to $\alpha$ SMApositive myofibroblasts in close contact with LPC (Figures 5 and $6 \mathrm{a}$ ). These results fit with the induction of TGF $\beta$ mRNA expression (Figure 6b) and the number of activated HSC and/or LPC that emerge in the liver after each treatment. Thus, the fivefold induction of TGF $\beta$ mRNA after 6 weeks of treatment in the $\mathrm{CCl}_{4}$ and AAF groups can be accounted by expression in HSC and LPC, respectively. The further induction up to 13 times in group $\mathrm{AAF} / \mathrm{CCl}_{4}$ can be related to TGF $\beta$ expression in both LPC and HSC, as a consequence of AAF-induced LPC expansion and $\mathrm{CCl}_{4}$-induced myofibroblastic activation; all these data reveal contribution of LPC to the development of liver fibrosis. To get better insight into TGF $\beta$ expression by LPC, we performed double-immunofluorescent detection of CK19 (red) and TGF $\beta$ (green) in liver sections from $\mathrm{AAF} / \mathrm{CCl}_{4}$-treated rats. By confocal analysis, there was a yellow signal in merged analysis, revealing TGF $\beta$ staining in CK19-positive cells forming ductular structures (Figure 6d). This result was also confirmed on consecutive liver frozen sections labeled with fluorescent CK19 and in situ hybridization for TGF $\beta$ mRNA (Supplementary Figure S2). Indeed, we noted a clear superimposition of TGF $\beta$ and CK19 signals in serial sections, predominantly in the portal ductular reaction and in septa expanding into the lobules, both areas containing a large population of LPC in AAF-treated animals. DAPI labeling also revealed that TGF $\beta$ mRNA was largely confined to small cells with ovoid nuclei, characteristic of LPC. Altogether, these results might strongly indicate that TGF $\beta$ was expressed by LPC.

\section{EMT of LPC}

To determine whether LPC undergo an EMT in cirrhotic liver, we studied these CK19-positive cells for the expression of mesenchymal markers in $\mathrm{AAF} / \mathrm{CCl}_{4}$ group after 6 weeks of treatment. Double-immunofluorescent experiments did not show any expression of $\alpha \mathrm{SMA}$ in CK19-positive LPC (no merging signals), neither in the ductular reaction arising in portal areas nor in the fibrous septa (Figure 7a). Thus, the aSMA-positive signal found in close contact of LPC corresponded to labeling of myofibroblastic HSC already described in the ductular reaction. ${ }^{3,11,15,39}$ Desmin staining, which revealed HSC in contact with LPC, extended beyond $\alpha$ SMA-labeled cells (Figure 7a), indicating that HSC detected in the ductular reaction are not fully activated into myofibroblastic cells. These results were confirmed by confocal analysis, which clearly showed the absence of $\alpha \mathrm{SMA}$ and desmin localization in CK19-labeled cells (Figure 7b). Additionally, expression of the fibroblast-specific protein
FSP1, which was also revealed around CK19-positive LPC (Figure 7a), did not co-stain in the same cells. Lack of colocalization of CK19 and collagen 1 (Figure 7a) suggests that the primary cells responsible for liver fibrogenesis are not LPC but activated HSC surrounding these cells. Therefore, we did not obtain any evidence showing that LPC might undergo $\mathrm{EMT}$ in $\mathrm{AAF} / \mathrm{CCl}_{4}$-treated rats.

\section{DISCUSSION}

Hepatic fibrosis is the liver response to chronic liver injury. It is characterized by excessive matrix deposition and accumulation of LPC, which are usually initiated in periportal areas, whatever is the location of the damage in the lobule. ${ }^{1,13,14}$ Classical models of fibrosis in rodents are based on chronic $\mathrm{CCl}_{4}$ intoxication leading to hepatocyte necrosis and matrix accumulation, which appeared initially around the central veins, without any LPC proliferation. ${ }^{40} \mathrm{AAF}$ administration associated with single $\mathrm{CCl}_{4}$ injection or partial hepatectomy is a classical experimental model to study LPC-dependent regeneration in rat. ${ }^{27}$ In this study, we developed a new experimental model, which recapitulates the events commonly observed in human fibrosis and is suitable to investigate the role of LPC in fibrogenesis. Indeed, the severity of liver fibrosis has been correlated to LPC expansion in humans ${ }^{12-14,28}$ and recently, unexpected activation of LPC compartment in Egr1 ${ }^{-1-}$ mice enhanced hepatic fibrosis after chronic $\mathrm{CCl}_{4}$ exposure. ${ }^{41}$ To achieve that goal, we combined an AAF treatment, known to induce regeneration from LPC, ${ }^{2,27}$ with repeated $\mathrm{CCl}_{4}$ injections, known to induce liver fibrosis in rodents. Combined AAF and $\mathrm{CCl}_{4}$ treatment led to extensive liver fibrosis and cirrhosis with marked LPC expansion, whereas $\mathrm{CCl}_{4}$ intoxication alone caused moderate fibrosis without expansion of LPC compartment. Unexpectedly, chronic and discontinuous AAF treatment by itself induced also an LPC expansion in the absence of an external mitogenic stimulus. Actually, low AAF doses generated low toxicity as revealed by slight induction of ALAT, but liver injury was accompanied by an increase of apoptosis. This is in line with the proposal that AAF metabolites are able to uncouple mitochondrial respiratory chain and open the permeability pore leading to apoptosis. ${ }^{42}$ As a consequence, injured hepatocytes eliminated by apoptosis might provide a sufficient signal to stimulate the LPC compartment while normal hepatocytes cannot proliferate due to AAF toxicity.

In all $\mathrm{AAF} / \mathrm{CCl}_{4}$-treated rats, accumulation of LPC in fibrous septa was associated with enhanced activation of desmin-positive HSC and expression of profibrotic genes such as collagen 1 and 3 , leading to cirrhosis. As recently reported, ${ }^{11}$ aSMA-positive cells were first detected in close association with LPC expansion in the portal region of the lobule at week 2. Activated HSC were observed later in necrotic centrilobular areas and in porto-central bridging fibrosis at week 6 . In contrast, very few $\alpha$ SMA-positive cells were detected in the liver of animals treated with $\mathrm{CCl}_{4}$ only, probably because of the low dose of $\mathrm{CCl}_{4}$ used in our experimental 
a
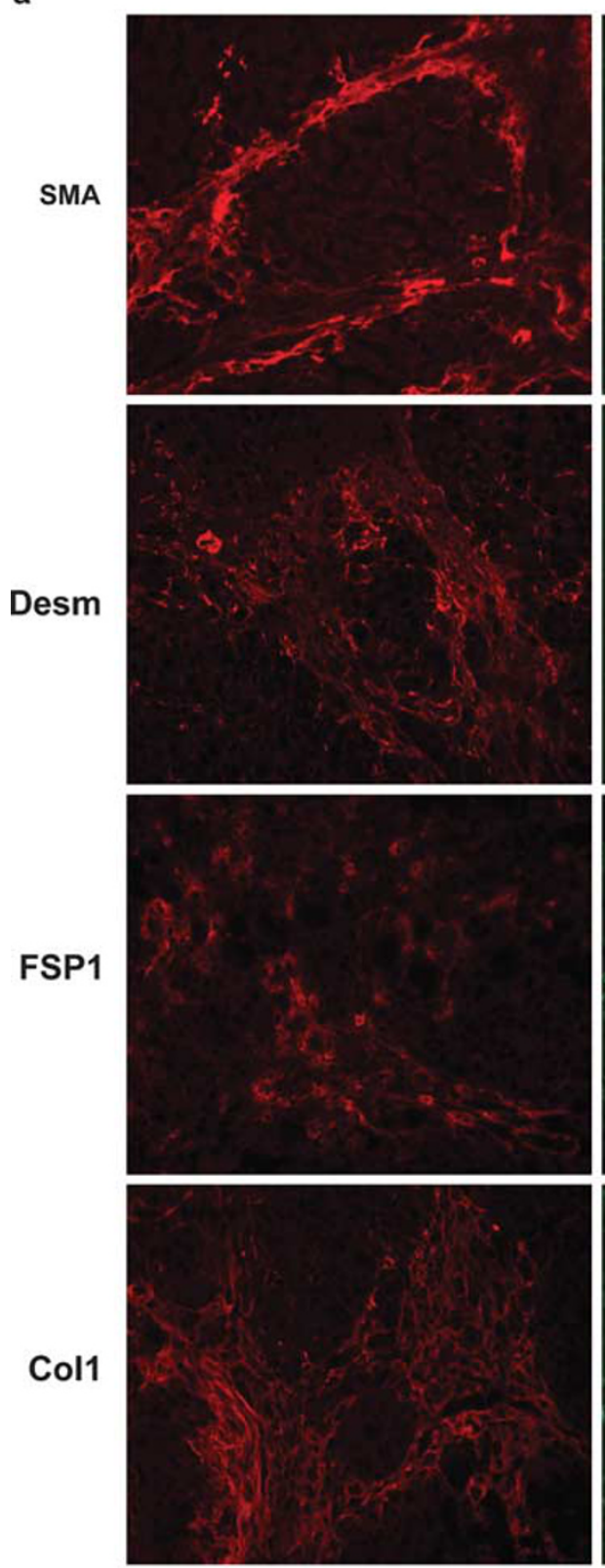

b

CK19/Desm
CK19
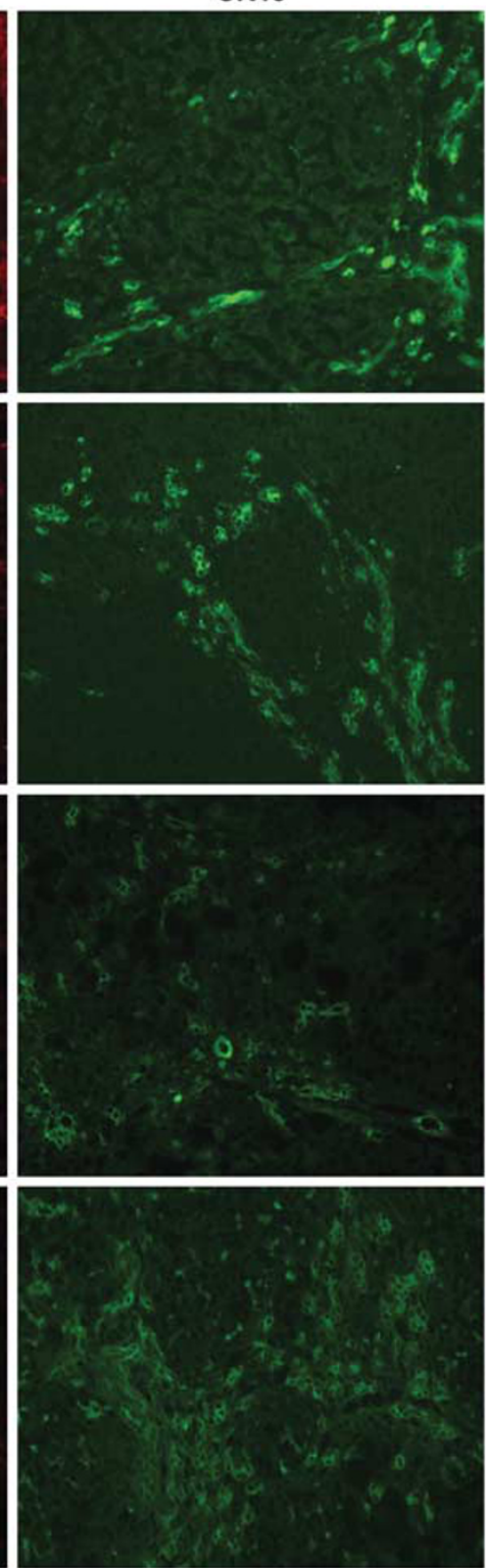

Merge
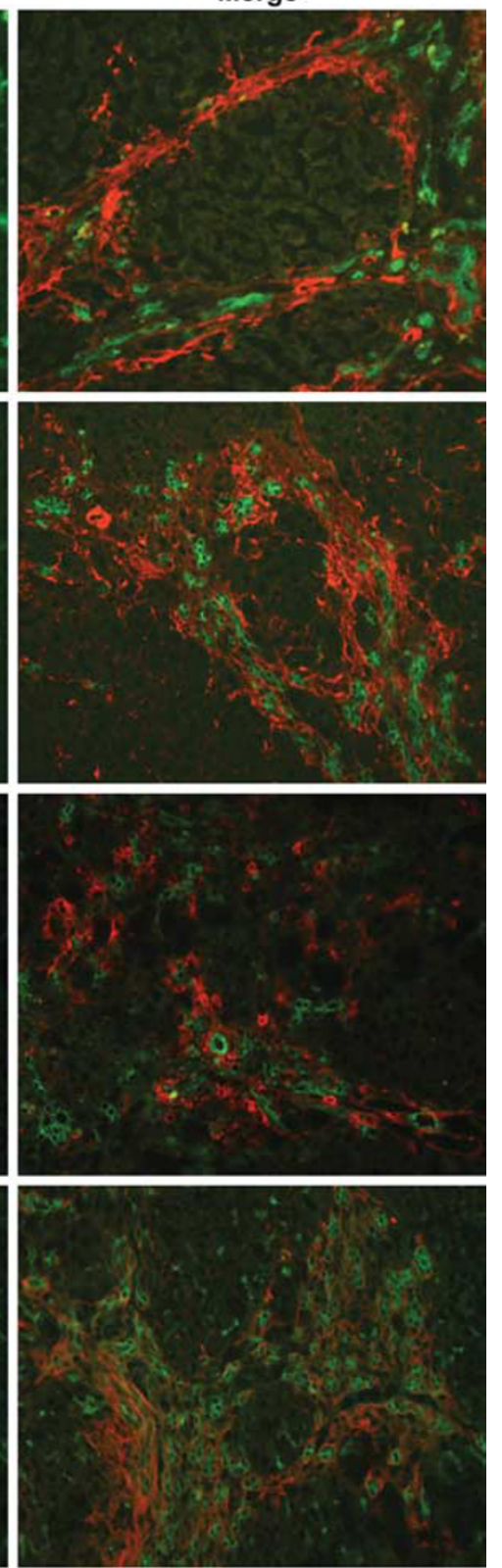

\section{CK19/SMA}

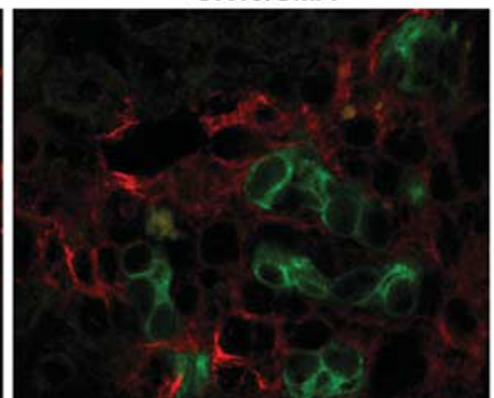

Figure 7 Immunolocalization of mesenchymal proteins on CK19-positive LPC from AAF/CCl-treated animals after 6 weeks of treatment. (a) Representative images of double immunofluorescence for CK19 (green) and myofibroblastic markers (red) aSMA, desmin, FSP1 and collagen 1 of two experiments from two rats (original magnification $\times 200$ ). No merging signals between any mesenchymal marker and CK19 could be obtained in LPC. (b) Confocal analysis confirmed the absence of mesenchymal markers in CK19-positive LPC that are surrounded by desmin- and $\alpha$ SMA-positive cells $(\times 630)$. 
conditions, which represented only $50 \%$ of the amount generally used in fibrogenic protocols. Since paracrine and autocrine secretion of TGF $\beta$ is the main factor involved in matrix deposition by activated HSC, ${ }^{8}$ reduced fibrosis in liver from $\mathrm{CCl}_{4}$-treated rats is in accordance with low level of TGF $\beta$ mRNA. Resident and recruited macrophages also have a critical role in myofibroblastic activation of HSC, notably by releasing factors including TGF $\beta .{ }^{1}$ However, the increased fibrogenic process in $\mathrm{AAF} / \mathrm{CCl}_{4}$-treated rats did not essentially depend on the inflammatory response, which remained moderate in our experimental setting and similar in both $\mathrm{CCl}_{4}$ and $\mathrm{AAF} / \mathrm{CCl}_{4}$ groups, as assessed by $\mathrm{CD} 68$ labeling, $\mathrm{TNF} \alpha$ and CCR2 mRNA levels. To investigate the underlying role of LPC on fibrosis, it was important to exclude a distinct effect in liver damage of combined $\mathrm{AAF} / \mathrm{CCl}_{4}$ treatment from $\mathrm{CCl}_{4}$ alone. A similar level of liver injury was achieved in both groups, as shown by similar serum ALT and similar apoptosis in liver extracts at any experimental time point. This probably excludes additional AAF-induced toxicity as a complicating factor in $\mathrm{AAF} / \mathrm{CCl}_{4}$-treated animals. Thus, defective HSC activation into $\alpha$ SMA-positive cells and reduced fibrosis in $\mathrm{CCl}_{4}$-treated rats seemed to be related to the lack of LPC compartment expansion.

Activation of LPC is a complex process that is not elucidated yet. It involves secretion of cytokines such as TNF $\alpha$ that activates the entry of quiescent stem cell in the cell cycle in a context where liver regeneration from hepatocytes is severely impaired as reported in $\mathrm{AAF} / \mathrm{CCl}_{4}$-treated rats. ${ }^{36}$ Other cytokines produced by immune cells in response to liver injury such as interferon- $\gamma$ have mitogenic effects on LPC and antiproliferative effects on hepatocytes. ${ }^{43}$ Interestingly, hedgehog (Hh) ligands released from dying hepatocytes can promote LPC expansion and the resistance of LPC to the anti-proliferative response of TGF $\beta$. They are probably other players of the LPC response in injured liver and by favoring activation of HSC or portal fibroblasts into myofibroblasts ${ }^{4-46}$ may also promote cirrhosis in $\mathrm{AAF} / \mathrm{CCl}_{4}$ group. Numerous studies have reported paracrine interactions between LPC and HSC or portal fibroblasts located in close proximity. ${ }^{2,11,14,15,47,48}$ Activated HSC ${ }^{18,49}$ and portal fibroblasts ${ }^{45}$ are a major source of growth factors for LPC and recent data established that myofibroblasts are required for LPC response $^{11,19}$ and are a component of the LPC niche. ${ }^{20}$ Conversely, it has not been clearly shown whether LPC could cause HSC or portal fibroblast activation. The $\alpha$ SMA staining, the most widely used technique that reveals myofibroblasts, could not distinguish in our study between both types of cells. In the present study, we demonstrated that LPC express TGF $\beta$, the most potent activator of quiescent $\mathrm{HSC}^{8}$ and portal fibroblasts ${ }^{50}$ into myofibroblasts, therefore contributing to hepatic fibrogenesis. The fact that TGF $\beta$ was also detected in LPC from rats treated with AAF alone in the absence of $\alpha$ SMA-positive cells close to LPC, points out that LPC and TGF $\beta$ alone are not sufficient to induce activation of HSC or of portal fibroblasts. In the group AAF, we observed an enhanced hepatic expression of collagen 4 and an accumulation of laminin (data not shown), two components of the basement membrane secreted by quiescent HSC in contact with LPC, ${ }^{3,20}$ which may account for the faint picrosirius red labeling around portal areas. In summary, these data suggest that LPC alone are not fibrogenic when there is no hepatocellular damage, and they emphasize the need of $\mathrm{CCl}_{4}$-induced injury to promote $\mathrm{HSC}$ activation and subsequent fibrosis. In other words, in addition to TGF $\beta$ secreted by LPC, the release of numerous factors from dying hepatocytes seems necessary to trigger the further myofibroblastic activation of HSC and the subsequent fibrogenic response.

The ability of LPC to transform into myofibroblasts through EMT is an interesting issue. ${ }^{51-53}$ The role of EMT in fibrosis was established in lung and kidney and, in the liver, transition of hepatocytes, biliary cells and HSC has also been already reported. ${ }^{22-26}$ TGF $\beta$, which we found secreted by LPC, is a well-known EMT inducer ${ }^{22,23,25}$ that could trigger LPC transition by an autocrine/paracrine pathway and provide a new potential mechanism of fibrosis. However, we could not demonstrate the expression of mesenchymal markers (ie $\alpha \mathrm{SMA}$, desmin and FSP1) in CK19-positive LPC cells from $\mathrm{AAF} / \mathrm{CCl}_{4}$-treated rats in vivo. Transition of $\mathrm{LPC}$ organized in ductular structures into isolated myofibroblasts could be difficult to identify by colocalization of epithelial and mesenchymal markers, particularly if the loss of epithelial characteristics occurs early during EMT process. For these reasons, proof of LPC undergoing EMT in vivo needs a genetic fate-mapping approach to track the fate of LPC during liver injury. Nevertheless, transition of LPC to myofibroblasts after treatment with TGF $\beta$ has indeed been previously obtained in vitro, using LPC isolated from rats fed a choline-deficient diet supplemented with ethionine. ${ }^{53}$

In a search of the capability of LPC to undergo EMT into HSC, we cultured human HepaRG LPC ${ }^{54}$ and followed their epithelial and fibroblastic phenotypic characteristics in response to TGF $\beta$. HepaRG underwent a phenotypic change from epithelial to mesenchymal-like cells in vitro on the basis of an increased expression of snail, $\alpha \mathrm{SMA}$ and collagens and a paralleled decrease of E-cadherin (unpublished data) as observed by Wang et $a l^{53}$ on rat LPC. Demonstration of EMT in vivo is at the heart of a controversy and some investigators consider that EMT observed in vitro could be an artifact of cell culture. ${ }^{55,56}$ Although isolated and cultured LPC possess some mesenchymal markers of HSC, such as collagen 1 and $3^{53}$ and $\alpha \mathrm{SMA},{ }^{48,51}$ an elegant fate-mapping study using the LPC marker Foxl1 demonstrated that all Foxl1-expressing cells and their progeny did not acquire a mesenchymal phenotype during LPC expansion in vivo. ${ }^{52}$ These Foxllpositive cells are surrounded by fibroblastic cells expressing elastin, desmin and $\alpha \mathrm{SMA}$, which reveals a potential cross-talk between LPC and these fibrogenic cells. In accordance with these data, we show that LPC neither acquire a mesenchymal phenotype through EMT in vivo nor directly 
participate to excessive ECM deposition. It remains that CK19-negative cells expressing mesenchymal markers were detected in close proximity to LPC, confirming that LPC are accompanied by $\alpha$ SMA-positive cells that derive from HSC or periportal fibroblasts. ${ }^{10,11,15}$ Other evidence suggests that HSC could differentiate into LPC with an intermediate phenotype, ${ }^{51,57}$ adding further complexity to the mechanisms by which HSC or LPC contribute to liver fibrogenesis. Nevertheless, mesenchymal-to-epithelial transition of HSC could not be demonstrated in liver fibrosis induced by bile duct ligation or $\mathrm{CCl}_{4}$ administration. ${ }^{58}$

In summary, we show that LPC expansion aggravates liver fibrosis. This strong fibrogenic response does not appear to be the direct consequence of hepatocellular lesions or inflammatory response, but seems to be due to the accumulation of TGF $\beta$-producing LPC, thus driving the myofibroblastic transformation of fibroblasts and/or HSC in injured liver. Fibrogenic properties of periportal LPC provide an explanation for the development of predominant periportal fibrosis, whatever is the primary location of hepatocellular damage, leading to porto-central fibrous septa progressing to cirrhosis.

Supplementary Information accompanies the paper on the Laboratory Investigation website (http://www.laboratoryinvestigation.org)

\section{ACKNOWLEDGEMENTS}

This work was supported by INSERM, University Paris-Est Creteil and Agence Nationale pour la Recherche (ANR-06-Physio-022-2). We are grateful to $X$ Decrouy from Platform for cell imaging (IMRB, Creteil) for technical support in confocal microscope.

\section{DISCLOSURE/CONFLICT OF INTEREST}

The authors declare no conflict of interest.

1. Ramadori G, Saile B. Portal tract fibrogenesis in the liver. Lab Invest 2004;84:153-159.

2. Paku S, Schnur J, Nagy $P$, et al. Origin and structural evolution of the early proliferating oval cells in rat liver. Am J Pathol 2001;158: 1313-1323.

3. Paku S, Nagy P, Kopper $L$, et al. 2-Acetylaminofluorene dosedependent differentiation of rat oval cells into hepatocytes: confocal and electron microscopic studies. Hepatology 2004;39:1353-1361.

4. Knight B, Matthews VB, Olynyk JK, et al. Jekyll and Hyde: evolving perspectives on the function and potential of the adult liver progenitor (oval) cell. Bioessays 2005;27:1192-1202.

5. Sell S. Comparison of liver progenitor cells in human atypical ductular reactions with those seen in experimental models of liver injury. Hepatology 1998;27:317-331.

6. Bird TG, Lorenzini S, Forbes SJ. Activation of stem cells in hepatic diseases. Cell Tissue Res 2008;331:283-300.

7. Schotanus BA, van den Ingh TS, Penning LC, et al. Cross-species immunohistochemical investigation of the activation of the liver progenitor cell niche in different types of liver disease. Liver Int 2009;29:1241-1252.

8. Friedman SL. Mechanisms of hepatic fibrogenesis. Gastroenterology 2008;134:1655-1669.

9. Fausto N, Campbell JS, Riehle KJ. Liver regeneration. Hepatology 2006:43(2 Suppl 1):S45-S53.

10. Svegliati-Baroni G, De Minicis S, Marzioni M. Hepatic fibrogenesis in response to chronic liver injury: novel insights on the role of cell-to-cell interaction and transition. Liver Int 2008;28:1052-1064.
11. Van Hul NK, Abarca-Quinones J, Sempoux C, et al. Relation between liver progenitor cell expansion and extracellular matrix deposition in a CDE-induced murine model of chronic liver injury. Hepatology 2009;49:1625-1635.

12. Lowes KN, Brennan BA, Yeoh GC, et al. Oval cell numbers in human chronic liver diseases are directly related to disease severity. Am J Pathol 1999;154:537-541.

13. Clouston $A D$, Powell EE, Walsh $M J$, et al. Fibrosis correlates with a ductular reaction in hepatitis C: roles of impaired replication, progenitor cells and steatosis. Hepatology 2005;41:809-818.

14. Richardson MM, Jonsson JR, Powell EE, et al. Progressive fibrosis in nonalcoholic steatohepatitis: association with altered regeneration and a ductular reaction. Gastroenterology 2007;133:80-90.

15. Knight B, Akhurst B, Matthews $\mathrm{VB}$, et al. Attenuated liver progenitor (oval) cell and fibrogenic responses to the choline deficient, ethionine supplemented diet in the BALB/c inbred strain of mice. J Hepatol 2007;46:134-141.

16. Clouston AD, Jonsson JR, Powell EE. Hepatic progenitor cell-mediated regeneration and fibrosis: chicken or egg? Hepatology 2009;49: 1424-1426.

17. Pi L, Oh SH, Shupe $\mathrm{T}$, et al. Role of connective tissue growth factor in oval cell response during liver regeneration after $2-\mathrm{AAF} / \mathrm{PHx}$ in rats. Gastroenterology 2005;128:2077-2088.

18. Akhurst B, Matthews V, Husk K, et al. Differential lymphotoxin-beta and interferon gamma signaling during mouse liver regeneration induced by chronic and acute injury. Hepatology 2005;41:327-335.

19. Pintilie DG, Shupe TD, Oh SH, et al. Hepatic stellate cells' involvement in progenitor-mediated liver regeneration. Lab Invest 2010;90: 1199-1208.

20. Lorenzini S, Bird TG, Boulter L, et al. Characterisation of a stereotypical cellular and extracellular adult liver progenitor cell niche in rodents and diseased human liver. Gut 2010;59:645-654.

21. Ruddell RG, Knight B, Tirnitz-Parker JE, et al. Lymphotoxin-beta receptor signaling regulates hepatic stellate cell function and wound healing in a murine model of chronic liver injury. Hepatology 2009;49:227-239.

22. Kaimori A, Potter J, Kaimori JY, et al. Transforming growth factor-beta1 induces an epithelial-to-mesenchymal transition state in mouse hepatocytes in vitro. J Biol Chem 2007;282:22089-22101.

23. Zeisberg $M$, Yang $C$, Martino $M$, et al. Fibroblasts derive from hepatocytes in liver fibrosis via epithelial to mesenchymal transition. J Biol Chem 2007;282:23337-23347.

24. Robertson H, Kirby JA, Yip WW, et al. Biliary epithelial-mesenchymal transition in posttransplantation recurrence of primary biliary cirrhosis. Hepatology 2007;45:977-981.

25. Rygiel KA, Robertson $\mathrm{H}$, Marshall $\mathrm{HL}$, et al. Epithelial-mesenchymal transition contributes to portal tract fibrogenesis during human chronic liver disease. Lab Invest 2008;88:112-123.

26. Battaglia S, Benzoubir N, Nobilet $\mathrm{S}$, et al. Liver cancer-derived hepatitis $C$ virus core proteins shift TGF-Beta responses from tumor suppression to epithelial-mesenchymal transition. PLoS ONE 2009; 4:e4355.

27. Petersen BE, Zajac VF, Michalopoulos GK. Hepatic oval cell activation in response to injury following chemically induced periportal or pericentral damage in rats. Hepatology 1998;27:1030-1038.

28. Roskams T, Yang SQ, Koteish A, et al. Oxidative stress and oval cell accumulation in mice and humans with alcoholic and nonalcoholic fatty liver disease. Am J Pathol 2003;163:1301-1311.

29. Lafdil F, Chobert MN, Deveaux V, et al. Growth arrest-specific protein 6 deficiency impairs liver tissue repair after acute toxic hepatitis in mice. J Hepatol 2009;51:55-66.

30. Lafdil F, Chobert MN, Couchie D, et al. Induction of Gas6 protein in CCl4-induced rat liver injury and anti-apoptotic effect on hepatic stellate cells. Hepatology 2006;44:228-239.

31. Mavier P, Martin N, Couchie D, et al. Expression of stromal cell-derived factor- 1 and of its receptor CXCR4 in liver regeneration from oval cells in rat. Am J Pathol 2004;165:1969-1977.

32. Julien B, Grenard P, Teixeira-Clerc F, et al. Antifibrogenic role of the cannabinoid receptor CB2 in the liver. Gastroenterology 2005;128:742-755.

33. Tullberg-Reinert $\mathrm{H}$, Jundt $\mathrm{G}$. In situ measurement of collagen synthesis by human bone cells with a sirius red-based colorimetric microassay: effects of transforming growth factor beta2 and ascorbic acid 2phosphate. Histochem Cell Biol 1999;112:271-276. 
34. Fausto N, Laird AD, Webber EM. Liver regeneration. 2. Role of growth factors and cytokines in hepatic regeneration. FASEB J 1995;9:1527-1536.

35. Knight B, Yeoh GC. TNF/LTalpha double knockout mice display abnormal inflammatory and regenerative responses to acute and chronic liver injury. Cell Tissue Res 2005;319:61-70.

36. Knight B, Yeoh GC, Husk KL, et al. Impaired preneoplastic changes and liver tumor formation in tumor necrosis factor receptor type 1 knockout mice. J Exp Med 2000;192:1809-1818.

37. Mitchell C, Couton D, Couty JP, et al. Dual role of CCR2 in the constitution and the resolution of liver fibrosis in mice. Am J Pathol 2009;174:1766-1775.

38. Braun L, Mead JE, Panzica M, et al. Transforming growth factor beta mRNA increases during liver regeneration: a possible paracrine mechanism of growth regulation. Proc Natl Acad Sci USA 1988;85:1539-1543.

39. Pham Van T, Couchie D, Martin-Garcia N, et al. Expression of matrix metalloproteinase-2 and -9 and of tissue inhibitor of matrix metalloproteinase-1 in liver regeneration from oval cells in rat. Matrix Biol 2008;27:674-681.

40. Zhao $X Y$, Wang BE, Li XM, et al. Newly proposed fibrosis staging criterion for assessing carbon tetrachloride- and albumin complexinduced liver fibrosis in rodents. Pathol Int 2008;58:580-588.

41. Pritchard MT, Nagy LE. Hepatic fibrosis is enhanced and accompanied by robust oval cell activation after chronic carbon tetrachloride administration to Egr-1-deficient mice. Am J Pathol 2010;176:2743-2752.

42. Neumann HG. Aromatic amines in experimental cancer research tissue-specific effects, an old problem and new solutions. Crit Rev Toxicol 2007;37:211-236.

43. Viebahn CS, Yeoh GC. What fires prometheus? The link between inflammation and regeneration following chronic liver injury. Int J Biochem Cell Biol 2008:40:855-873.

44. Nguyen LN, Furuya MH, Wolfraim LA, et al. Transforming growth factor-beta differentially regulates oval cell and hepatocyte proliferation. Hepatology 2007;45:31-41.

45. Omenetti A, Yang L, Li YX, et al. Hedgehog-mediated mesenchymalepithelial interactions modulate hepatic response to bile duct ligation. Lab Invest 2007;87:499-514.
46. Jung Y, Witek RP, Syn WK, et al. Signals from dying hepatocytes trigger growth of liver progenitors. Gut 2010;59:655-665.

47. Evarts RP, Nakatsukasa H, Marsden ER, et al. Cellular and molecular changes in the early stages of chemical hepatocarcinogenesis in the rat. Cancer Res 1990;50:3439-3444.

48. Yovchev MI, Grozdanov PN, Zhou H, et al. Identification of adult hepatic progenitor cells capable of repopulating injured rat liver. Hepatology 2008;47:636-647.

49. Knight B, Lim R, Yeoh GC, et al. Interferon-gamma exacerbates liver damage, the hepatic progenitor cell response and fibrosis in a mouse model of chronic liver injury. J Hepatol 2007;47:826-833.

50. Li Z, Dranoff JA, Chan EP, et al. Transforming growth factor-beta and substrate stiffness regulate portal fibroblast activation in culture. Hepatology 2007;46:1246-1256.

51. Sicklick JK, Choi SS, Bustamante M, et al. Evidence for epithelialmesenchymal transitions in adult liver cells. Am J Physiol Gastrointest Liver Physiol 2006;291:G575-G583.

52. Sackett SD, Li Z, Hurtt R, et al. Foxl1 is a marker of bipotential hepatic progenitor cells in mice. Hepatology 2009;49:920-929.

53. Wang $P$, Liu $T$, Cong $M$, et al. Expression of extracellular matrix genes in cultured hepatic oval cells: an origin of hepatic stellate cells through transforming growth factor beta? Liver Int 2009;29:575-584.

54. Parent $R$, Marion MJ, Furio $L$, et al. Origin and characterization of a human bipotent liver progenitor cell line. Gastroenterology 2004;126:1147-1156.

55. Taura K, Miura K, Iwaisako K, et al. Hepatocytes do not undergo epithelial-mesenchymal transition in liver fibrosis in mice. Hepatology 2010;51:1027-1036.

56. Duffield JS. Epithelial to mesenchymal transition in injury of solid organs: fact or artifact? Gastroenterology 2010;139:1081-1083, e1081-e1085.

57. Yang L, Jung $Y$, Omenetti A, et al. Fate-mapping evidence that hepatic stellate cells are epithelial progenitors in adult mouse livers. Stem Cells 2008;26:2104-2113.

58. Scholten D, Osterreicher $\mathrm{CH}$, Scholten $\mathrm{A}$, et al. Genetic labeling does not detect epithelial-to-mesenchymal transition of cholangiocytes in liver fibrosis in mice. Gastroenterology 2010;139:987-998. 